\title{
Area Selective Chemical Vapor Deposition of Metallic Films using Plasma Electrons as Reducing Agents
}

\author{
Hama Nadhom
}





\title{
Area Selective Chemical Vapor Deposition of Metallic Films using Plasma Electrons as Reducing Agents
}

\author{
Hama Nadhom \\ Department of Physics, Chemistry and Biology (IFM) \\ Linköping University \\ SE-581 83 Linköping, Sweden \\ Linköping 2021
}


(oc) EY-No This work is licensed under a Creative Commons AttributionNonCommercial 4.0 International License.

https://creativecommons.org/licenses/by-nc/4.0/

(C) Hama Nadhom, 2021

ISBN: 978-91-7929-632-2

ISSN 0345-7524

Printed by LiU-Tryck, Linköping, 2021 


\section{Abstract}

Metallic films are used to improve optical, chemical, mechanical, magnetic, and electrical properties and are therefore of high importance in many applications, from electronics and catalysis, environmental protection and health, to wearable and flexible electronic materials. Many of these applications, however, require that the metal films are deposited uniformly on topographically complex surfaces and structures. Some form of chemical vapor deposition (CVD) where the deposition is governed by the surface chemistry is needed for uniform film deposition on topographically complex surfaces. Furthermore, area selective deposition (ASD) has gained large considerations lately, where films deposited only on specified areas of the substrate, and not on others, simplifies the processing significantly and opens the way for less complex fabrication of, for instance, nanoscaled electronics. ASD occurs when the surface chemical reactions are disabled on selected areas of the substrate. Since the metal centers in CVD precursor molecules typically have a positive valence, a reductive surface chemistry is required to form a metallic film. This is usually done by using a second precursor, i.e., a molecular reducing agent. The negative standard reduction potential of the first-row transition metals ( $\mathrm{Ti}, \mathrm{V}, \mathrm{Cr}, \mathrm{Mn}, \mathrm{Fe}, \mathrm{Co}$, and $\mathrm{Ni}$ ) means that $\mathrm{CVD}$ of these metals requires either very high temperatures or very powerful molecular reducing agents. This thesis describes a new low temperature CVD method for depositing metallic films where instead free electrons in a plasma discharge are utilized to reduce the metal centers of chemisorbed precursor molecules. By applying a positive bias voltage to the substrate holder, the plasma electrons are attracted to the substrate for electron-precursor interactions. This was demonstrated by successfully depositing iron, cobalt, and nickel films from their corresponding metallocene precursors. The electrical resistivity of the substrate and the polarity of the substrate bias were shown to play an important role in depositing metallic films with this CVD approach. The experimental results show that films deposited, with $+40 \mathrm{~V}$ bias voltage, on silver substrates contain substantially higher metal concentration compare to films deposited on silicon substrates. Deposition on electrically insulating silicon dioxide substrates however yielded no detectable amount of metal atoms on the substrate surface. This indicates that electron current through the substrate is essential to grow metal films in this CVD process. The effect of the electrical resistivity of the substrate was studied for ASD. The new CVD method is shown to be inherently area selective from the surface electrical resistivity by depositing iron from ferrocene on silicon dioxide substrate partially coated with silver. No, or very small, detectable amount of metal atoms could be found 
on areas with high resistivity, whereas several hundred nm thick iron films are deposited on areas with low resistivity. The only heating of the substrate emanates from the electric current from the plasma through the substrate holder, resulting in a slight heating to $35-50{ }^{\circ} \mathrm{C}$, depending on the substrate bias voltage. This was regarded as the deposition temperature. Such low deposition temperature was exploited to achieve ASD by a masking approach with different temperature sensitive materials such as polydimethylsiloxane (PDMS), polymethylmethacrylate (PMMA), polystyrene (PS), Parafilm, Kapton tape, Scotch tape, and office paper. These materials were used to mask area of the substrate in the new CVD method as demonstrated by depositing iron from ferrocene on partially masked silver substrates.

All initial experiments rendered only a phenomenological understanding of the new CVD process. Therefore, a quartz crystal microbalance (QCM) system was modified, by the addition of a positive bias voltage, and used to further understand the chemical and physical processes controlling the deposition process. The results show that differences in film deposition with different deposition parameters, such as plasma power and bias voltage, can be observed using the new QCM approach where the QCM crystal indeed works as a substrate in our new CVD process.

In summary, a new CVD concept has been developed for metallic thin films. This method uses the free plasma electrons as reducing agents and can also be utilized for ASD of metal thin films. This opens new possibilities for robust and inexpensive metal-on-metal deposition, ranging from nano- to macroscale dimensions. 


\section{Populärvetenskaplig Sammanfattning}

En tunnfilm är ett skikt av ett eller flera material med en tjocklek som kan vara mellan 1 nanometer $\left(\mathrm{nm}=10^{-9} \mathrm{~m}\right)$ och upp till några mikrometer $\left(\mu \mathrm{m}=10^{-6} \mathrm{~m}\right)$. Som jämförelse är diametern på en människas hårstrå ca. $75000 \mathrm{~nm}$, eller $75 \mu \mathrm{m}$. Tunna metallfilmer används främst för att förbättra andra materialegenskaper, t.ex. optiska, kemiska, mekaniska, magnetiska och elektriska egenskaper. En spegel är ett bra exempel där en glasskiva beläggs med ett tunt lager av aluminium för reflektion. Tunna metalliska filmer har viktiga roller $\mathrm{i}$ många tillämpningar, de används inom katalys, miljöskydd och hälsa, samt inom elektronik. Många av dessa applikationer kräver dock en helt jämntjock metallfilm på komplexa ytor och strukturer. Ett sätt att deponera metallfilmer på sådana ytor och strukturer är att använda en så kallad kemisk ångdeponering, eller på engelska chemical vapor deposition (CVD). CVD är en metod som använder sig av kemiska reaktioner av molekyler som innehåller atomerna för det önskade filmmaterialet. Dessa molekyler, som kallas för källmolekyler, får reagera i gasfasen och på ytan där filmen ska deponeras för att skapa en tunnfilm via kemiska reaktioner. Metallen i källmolekylen är typiskt i ett oxiderat tillstånd, metallen saknar då elektroner och är formellt en jon, vilket innebär att de måste reduceras, alltså få elektroner, genom en kemisk reaktion på filmytan för att filmen ska bli metallisk. Detta görs vanligtvis med hjälp av en annan molekyl, ett så kallat molekylärt reduktionsmedel, som reagerar genom att lämna över elektroner. CVD av oädla metaller, t.ex. Ti, V, Cr, Mn, Fe, Co och Ni kräver antingen mycket höga temperaturer eller ett kraftfullt reduktionsmedel. Detta beror på deras negativa reduktionspotential, vilket betyder att reaktionen är svår och inte sker spontan. Denna avhandling beskriver en ny lågtemperatur CVD-metod för att deponera metallfilmer där fria elektroner $i$ en plasmaurladdning används för att reducera metalljonerna i de adsorberade källmolekylerna. Plasmaelektronerna dras till substratet genom att en elektriskspänning appliceras på substrathållaren. Detta demonstrerades genom att deponera järn-, kobolt- och nickelfilmer. Substratets elektriska resistivitet och polariteten på substratspänningen har visat sig spela en viktig roll vid deponering av metallfilmer med denna CVD-metod. De experimentella resultaten visar elektronströmmen från plasmat måste kunna gå genom substratet för att metallfilmer ska växa i denna CVD process. Detta utnyttjades för att kunna skapa en areaselektiv deponering (ASD) för att deponera metallfilmen endast på fördefinierade områden av substratet och inte på andra. ASD har fått stora uppmärksamhet på senare tid då det kan förenkla proceduren för att tillverka elektronik avsevärt. Eftersom denna CVD-metod är beroende av att 
plasmaelektronerna kan inte bara ledas till utan också från substratet så har effekten av substratets elektriska resistivitet studerats för ASD. Metoden visades vara area-selektiv från ytans elektriska resistivitet genom att deponera järn på ytor av kiseldioxid, som har mycket hög elektrisk resistivitet, delvis belagt med silver som har mycket låg elektrisk resistivitet. Ingen eller mycket liten detekterbar mängd metallatomer kunde hittas på områden med hög resistivitet, medan flera hundra nm tjocka järnfilmer deponerades på områden med låg resistivitet. Den låga deponeringstemperaturen i den nya CVD-metoden utnyttjades för att göra ASD genom att maskera substratet med olika material. Billiga och temperaturkänsliga material, såsom polydimetylsiloxan (PDMS), polymetylmetakrylat (PMMA), polystyren (PS), Parafilm, Kaptontejp, kontorstejp och kontorspapper kan användas som maskeringsmaterial. Inga filmer deponerades på de maskerade områden medan flera hundra nm tjocka järnfilmer deponerades på områden utan maskering.

De första experimenten gav endast en fenomenologisk förståelse för den nya CVD-processen. Därför har en kvartskristallmikrobalanssensor (ofta kallad QCM-sensor efter engelskans quartz crystal microbalance) modifierats för att kunna applicera en positiv elektrisk spänning på den. Denna modifierade QCM-sensor kan sedan användas för att ytterligare förstå de kemiska och fysikaliska processerna som styr deponeringsprocessen. Filmdeponering med olika depositionsparametrar, såsom plasmaeffekt och elektriskspänning, kan observeras med hjälp av den nya QCM-metoden där QCM-kristallen fungerar som ett substrat för vår nya CVD-process. Sammanfattningsvis har ett nytt CVD-koncept utvecklats för tunna metallfilmer. Denna metod använder de fria plasmaelektronerna som reduktionsmedel och kan också användas för area selektiv deponering av tunna metallfilmer. Detta öppnar nya möjligheter för robust och kostnadseffektiv deponering av metall på metall, allt från nano- till makro-dimensioner. 


\section{ملخص علمي}

الغشاء الرقيق عبارة عن طبقة من مادة واحدة او اكثر بسمك يتراوح بين نـانومتر واحد وبضعة ميكرومتر ـ كمقارنـة

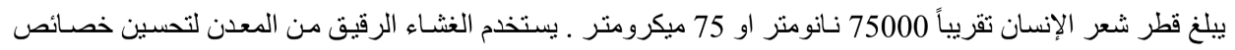

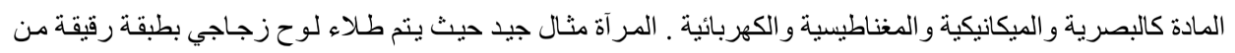
الألمنيوم لانعكاس الضوء (الصورة) . الاغشية المعدنية الرقيقة لها أدو ار مهمة في العديد من التطبيقات من الاككترونيات

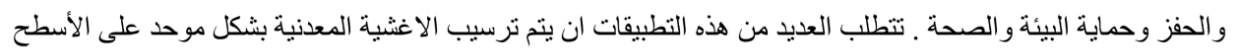

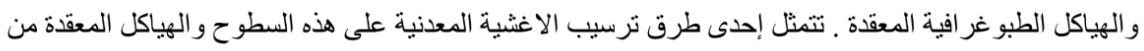
استخدام مايسمى بترسيب البخار الكيميائي (chemical vapor deposition, CVD) .

الترسيب البخـار الكيميائي هي طريقة استخدام التفاعلات الكيميائية للجزيئات التي تحتوي على ذرات مـادة المعدن المطلوبة ـ يسمح لهذه الجزيئات التي تسمى جزيئات المصدر بالتفاعل في الطور الغازي و على السطح حيث يتم ترسيب

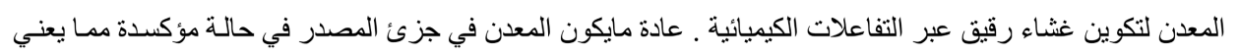

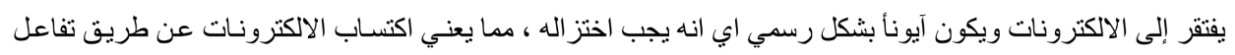

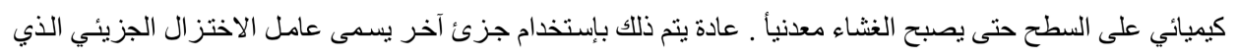

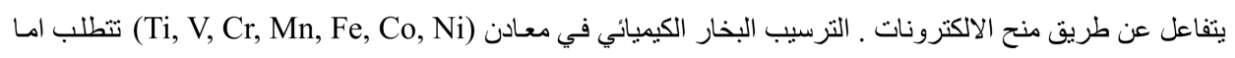

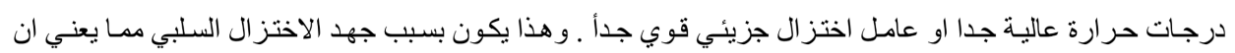
التفاعل صعب و لا بحدث تلقائياً.

تصف هذه الاطروحة طريقة جديدة لترسيب البخار الكيميائي ذات درجة حرارة منخفضة لترسيب الاغشية المعدنية

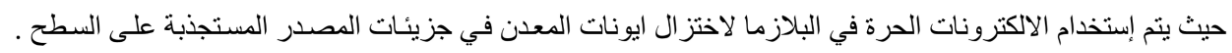

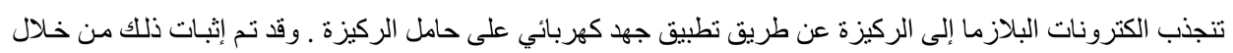
ترسيب اغشية الحديــ و الكوبالت و النيكل (Fe, Co, Ni) . تم اثبـات ان المقاومـة الكهربائيـة وقطبيـة الجهد الكهربـائي

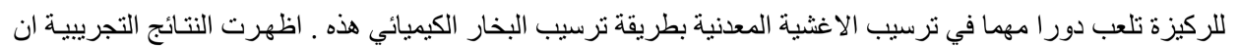

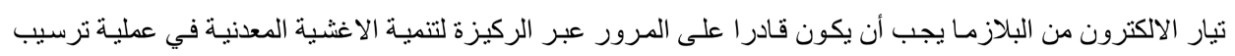

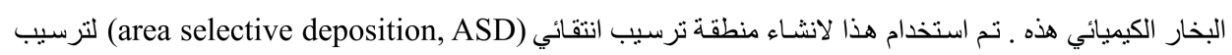
غشاء المعادن فقط على مناطق محددة من الركيزة وليس على مناطق اخرى ـ اكتسبت هنطقة التسيب الانتقائي اهتمامـات كبيرة في الآونة الأخيرة حيث يمكنه تسيل إجر اءات تصنيع الاكترونيات ـ نظر الان طريقة ترسيب البخار الكيميائي هذه ونه

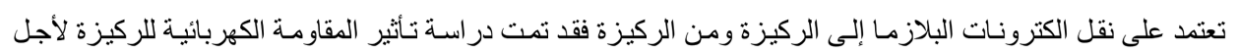

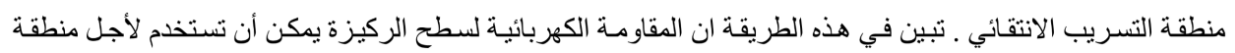
الترسيب الانتقائي خـال ترسيب الحديد على اسطح ثنائي اكسيد السيليكون (التي تتميز بمقاومـة كهربائية عاليـة جدا)

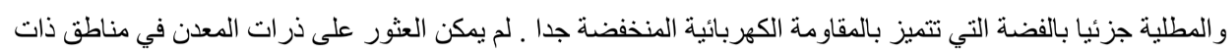

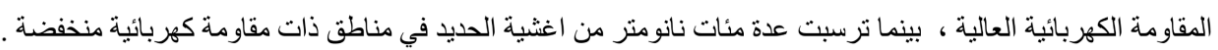


استخدمت درجة حر ارة الترسيب المنخفضة في طريقة الترسيب البخاري الكيميائي الجديدة لأجل منطقة الترسيب الانتقائي بطريقة أخرى و هي إخفاء الركيزة بمو اد مختلفة غير مكلفة وحساسـة لدرجـة الحر ارة مثل بولي ثنائي ميثبل السيلوكز ان(polydimethylsiloxane, PDMS) وبولي ميثيل كريلات (polymethylmethacrylate, PMMA) و البوليسـترين (polystyrene, PS) وبــار افيلم (karafilm) وشـريط لاصـق كـابتون (kapton) وشـريط لاصـق سكوتش (Scotch tape) وورق المكتب ـ لم توجد معادن مترسبة على المناطق المخفية بينما ترسبت اغشية من الحديد بسمك مئات نانومتر على المناطق الغير مخفية . قدمت التجارب الأولية فقط فهما ظاهريا لعملية ترسيب البخار الكيميائي الجديدة . لذلك تم استخدام ميزان دقيق بلورة

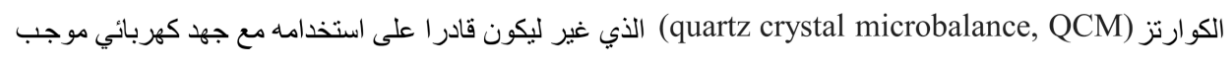

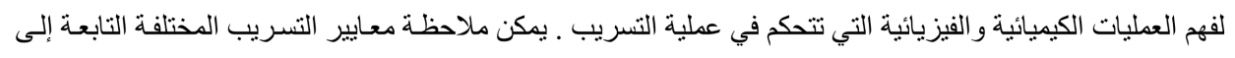

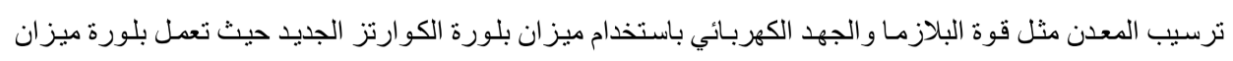
الكو ارتز كركيزة لعملية ترسيب البخار الكيمبائي الجديدة هذه .

باختصـار ، تم تطوير ترسيب بخار كيميائي جديد للاغشية المعدنية الرقيقة ـ تستخدم في هذه الطريقة الجديدة

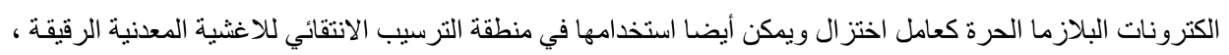
هذا يقتح إمكانيات جديدة و غير مكلفة لترسيب معدن على معدن . 


\section{Preface}

This thesis summarizes my research work done at the Chemistry Division of the Department of Physics, Chemistry and Biology (IFM) at Linköping University, Linköping, Sweden, from March 2016 to June 2021. The focus of this work was to develop a new CVD method of metal films that uses plasma electrons as reducing agents instead of molecular reducing agents. The system was then further exploited for area selective deposition of metal-on-metal.

The work presented herein was financed by the Swedish Research Council (VR) under Contracts 2015-03803 and 2019-05055, and the CeNano program at Linköping University. 


\section{Acknowledgement}

First of all, I would like to express my genuine gratitude and appreciation to Henrik Pedersen, my supervisor, for giving me the opportunity to do this interesting and exciting project. Also, for his guidance, support, and encouragement.

I would like to greatly thank Daniel Lundin, my co-supervisor, for his great help and contribution to the project in the last years.

I would also like to thank Kostas Sarakinos, my co-supervisor, very much for his help and involvement in the project, and for his group's cooperation (Andreas Jamnig and Nikolaos Pliatsikas).

Many thanks to the members of the Pedersen group. Polla (GD) Rouf (for all the help with the analysis, and for all the fun both in work and outside work), Rouzbeh Samii (for all the good time in the office and for all the candy), Laurent Souqui (a former member, for all the help, discussions, and the fun times), Karl Rönnby, Sachin Sharma, Jing-Jia Huang, Christian Militzer, Arun Haridas Choolakkal, Anton Persson, Hsu Chih-Wei, and Pentti Niiranen (future member, for his help, sorry for the stress).

I also give special thanks to Nathan (GP) O'Brian (also a Pedersen group member) for all the help, knowledge, discussions, and the fun times both in work and outside work, thank you buddy.

I would like to acknowledge all my friends and colleagues from the Chemistry Department, the Thin Film Division, and Agora Materiae at IFM (LiU).

To my family, thank you for your never-ending love, support and encouragement throughout all years. To my parents (the main motivation of my doctoral study): thank you for being my role model.

Last but not least, I would like to thank my beautiful wife Bahar E. Nadhom for her understanding, support, encouragement and love throughout all these years. And to my three years old son Rowan: thank you for adding so much to my life and for making the difficult times easy without knowing it.

\section{Hama Nadhom}

Writing at Linköping, $10^{\text {th }}$ of May 2021, during the COVID-19 pandemic. Having this done and with $23{ }^{\circ} \mathrm{C}$ outside, it is time to take my HD for a freedom ride. 


\section{List of Articles}

\section{$\underline{\text { Paper I: }}$}

Chemical vapor deposition of metallic films using plasma electrons as reducing agents

Hama Nadhom, Daniel Lundin, Polla Rouf, and Henrik Pedersen.

Journal of Vacuum Science \& Technology A 38, (2020) 033402.

I planned and preformed the depositions after discussions with my supervisor. I preformed all the electrical and SEM measurements. I analyzed all the data from SEM and XPS. I participated in discussions with the co-authors, wrote most of the first version of the manuscript and finalized it according to the co-author's comments.

\section{Paper II:}

Area selective deposition of metals from the electrical resistivity of the substrate

Hama Nadhom, Robert Boyd, Polla Rouf, Daniel Lundin, and Henrik Pedersen.

The Journal of Physical Chemistry Letters 12, (2021) 4130-4133.

I planned and preformed the depositions after discussions with my supervisor. I preformed all the measurements and analyzed all the data, apart from TEM. I participated in discussions with the co-authors, wrote the manuscript and finalized it according to the co-author's comments.

\section{Paper III:}

Area selective deposition of iron films using temperature sensitive masking materials and plasma electrons as reducing agents

Hama Nadhom, Yusheng Yuan, Polla Rouf, Niclas Solin, and Henrik Pedersen.

Accepted by Journal of Vacuum Science \& Technology A.

I planned and preformed the depositions after discussions with my supervisor. I preformed all the electrical and SEM measurements. I analyzed all the data from SEM and XPS. I wrote the manuscript and finalized it according to the co-author's comments. 


\section{Paper IV:}

Biased quartz crystal microbalance method for studies of CVD surface chemistry induced by plasma electrons

Pentti Niiranen, Hama Nadhom, Michal Zanaska, Robert Boyd, Polla Rouf, Daniel Lundin, and Henrik Pedersen.

In manuscript.

I actively participated in the planning and the experiments. I participated in the discussion of the results with co-authors and analyzed the XPS data. I wrote the manuscript in collaboration with the other authors. 


\section{Table of Contents}

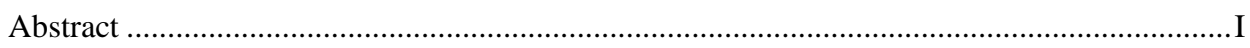

Populärvetenskaplig Sammanfattning .............................................................................. III

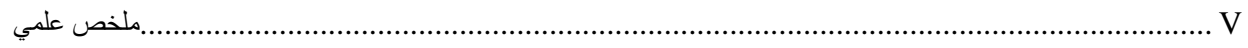

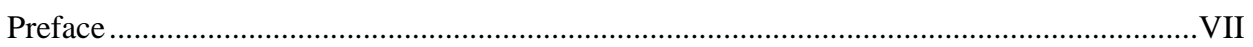

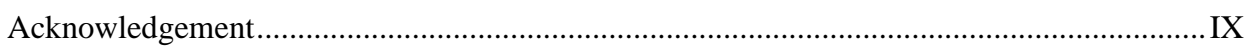

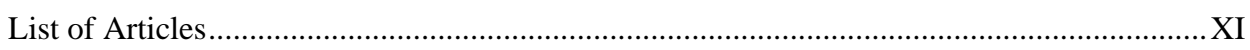

Table of Contents ................................................................................................ XIII

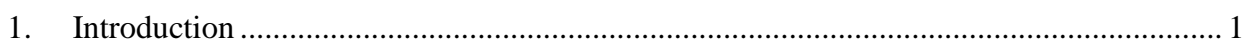

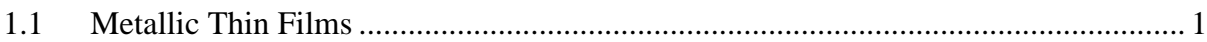

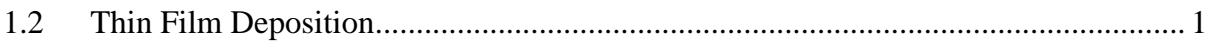

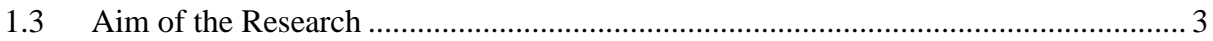

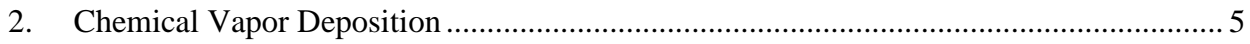

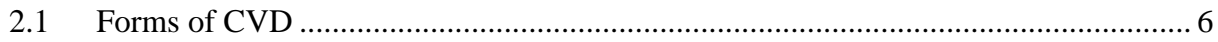

2.2 Plasma-Enhanced Chemical Vapor Deposition......................................................... 8

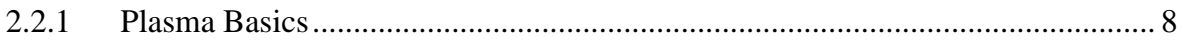

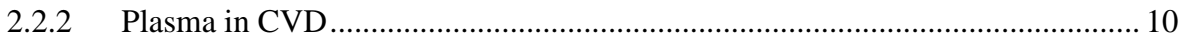

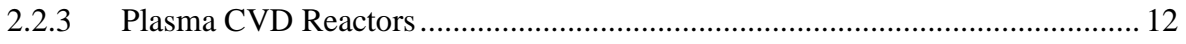

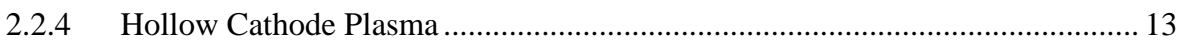

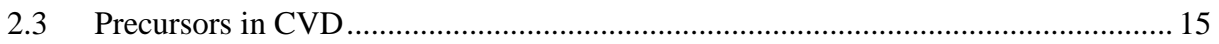

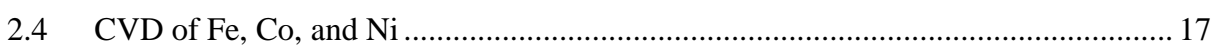

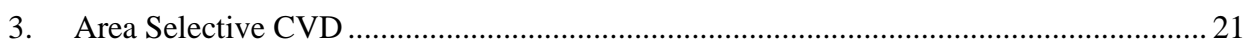

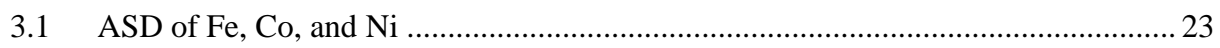

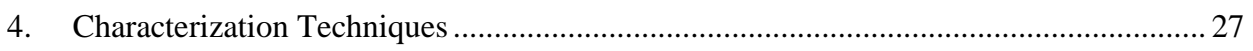

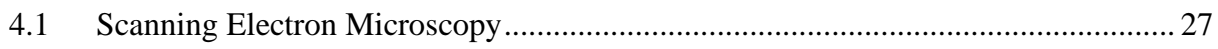

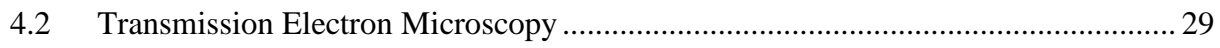

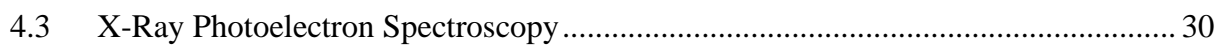

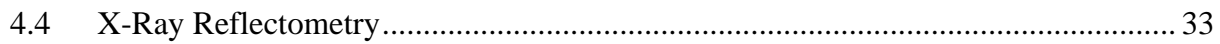

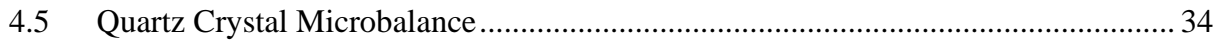

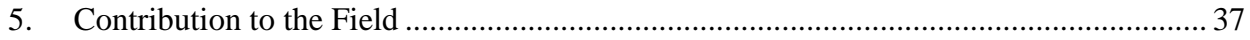

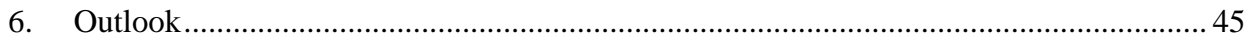

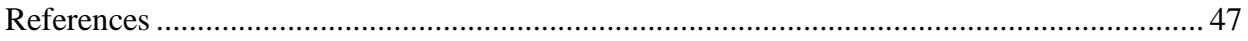





\section{Introduction}

\subsection{Metallic Thin Films}

A thin film is a layer, or multilayers, of material(s) with a thickness ranging from fractions of nanometer to a few micrometers. Thin metallic films are very common in different applications and products and have become an important aspect in our daily life. For instance, thin metallic films can be found in optical application (e.g., reflective, anti-reflective, and scratch resistant coatings), protection application (e.g., corrosion and wear resistant coatings), and in electronic applications (e.g., conductive materials in semiconductors, interconnections, and contacts), etc. Thin metallic films are usually deposited on other materials (bulk materials) to uniquely modify the bulk material properties, such as chemical, physical, optical, mechanical, and electrical properties, where such modification cannot be achieved in other ways. Thin films have been used for thousands of years for different purposes [1,2], and today they play a crucial role in many advanced technological applications, especially in electronics. The continuous miniaturization and complexification in electronics components and features require fundamental research in thin films, hence making it an important field in material science. One aspect that has gained large attention lately is area selective deposition (ASD), where films deposited only on specified areas of the substrate and not on others, simplifies the processing significantly and opens the way for less complex fabrication of, for instance, micro- and nanoscaled electronics.

\subsection{Thin Film Deposition}

Thin films can be produced by various methods, such as evaporation, electroplating, physical vapor deposition, chemical vapor deposition, and the combination of these methods. Which method to use depends on the film requirements, such as structure, composition, thickness, application, cost, etc. Here, physical vapor deposition and chemical vapor deposition are briefly described.

In physical vapor deposition (PVD), atoms, from a raw material in solid phase called target, are evaporated, or sputtered, by particle bombardment. The evaporated atoms are then transported 
to the substrate surface where they form a film by condensation. PVD is a line-of-sight technique that can produce high quality films. Almost all types of inorganic materials can be deposited on any type of substrates. Also, PVD is an environmentally friendly technique that does not produce toxic and hazardous by-products. PVD, however, requires high vacuum and is usually slow compare to, e.g., CVD for thicker films. In addition, films deposited by PVD usually suffer from uniformity and conformality issues, and because PVD is a line-of-sight technique, it is incapable of coating complex surfaces and structures. There are different PVD techniques, and the most common ones are magnetron sputtering and arc evaporation [3-5].

In chemical vapor deposition (CVD), volatile gases (called precursors) containing the desired atoms for film formation are provided with energy (e.g., heat, or plasma) and undergo gas-phase, and surface, chemical reactions in a vacuum chamber, resulting in reactive species that diffuse and chemically interact with a surface to form a film. Because CVD relies on chemical reactions, it is not a line-of-sight technique, which makes it an excellent method to coat complex surfaces and structures with films. In addition, CVD is capable of depositing a wide range of inorganic and organic materials. It is also a fast method, especially when higher film thicknesses are required. Such advantages make CVD a popular technique in industry. However, CVD usually operates at high temperatures (to initiate the chemical reactions), meaning that it is unsuitable to coat temperature sensitive materials. Nevertheless, this issue can be solved by using, e.g., plasmas as source of energy, reducing the temperatures significantly. Another issue in CVD is the handling of the precursors and by-products that might be hazardous and corrosive [6, 7]. Further description of CVD, including plasma CVD, are described in Chapter 2 (Chemical Vapor Deposition) of this thesis.

Furthermore, Plasmas can be utilized in both CVD and PVD for thin film processing. Plasmas can, for instance, provide the sufficient energy required for film deposition, hence reducing the deposition temperatures in CVD. Plasma can also improve film quality (by supplying energy to the film, e.g., ion bombardment) and growth rate in both CVD and PVD [7]. Regardless the method used, controlling the film properties, by controlling the deposition process, is a difficult task, and becomes very complex when plasmas are involved. 


\subsection{Aim of the Research}

The first purpose of this research is to develop a new low temperature CVD method that uses electrons from an inert gas ( $\mathrm{Ar}$ ) plasma as reducing agents to deposit metal films. Experiments have been conducted to demonstrate the new CVD method by depositing challenging transition metals with negative reduction potential, i.e., first-row transition metals, using iron, cobalt, and nickel as a proof of concept. Moreover, to get an insight and an understanding of the chemical and physical processes that control the deposition process, a positively biased quartz crystal microbalance was developed.

The other purpose of this research is to employ the newly developed CVD method for area selective deposition. Two approaches have been investigated and carried out: one is by utilizing the electrical resistivity properties of the substrate, by depositing iron films on substrate with high resistive material partially coated with low resistive material; and the other approach is by masking the substrate with simple and temperature sensitive polymer-based materials. 


\section{Chemical Vapor Deposition}

Chemical vapor deposition (CVD) is a general name for a deposition technique where the formation of thin films, from vapour phase, on a substrate take place by chemical reactions. The process involves chemical reactions between volatile compounds, such as gases, containing the metal in desire. Such compounds are usually called precursors.

Generally, there are two kinds of chemical reactions in CVD: gas phase reactions and surface reactions. The gas phase reactions take place where the precursors interact and react with each other in the gas phase and form new compounds. The surface reactions take place when the new formed compounds interact with the surface of the substrate and form a film. CVD are very complex and involve many other processes and reactions such as: evaporation and transport of the precursors into the reactor; gas phase reactions of the precursors to produce reactive products and by-products; mass transport of the reactants to the substrate; adsorption of the reactants on the substrate surface; surface diffusion, nucleation and surface chemical reactions for film formation; desorption and mass transport of the by-product and residual products from the reaction zone. Figure 2.1 shows a schematic drawing of the CVD processes and reactions.

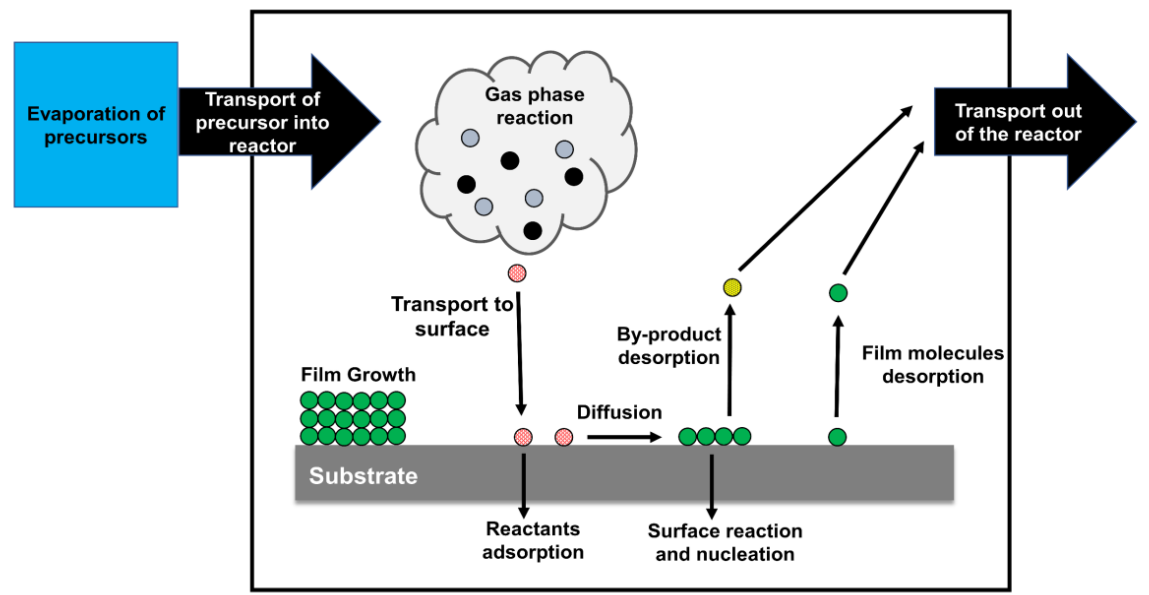

FIGURE 2.1. A schematic of the different processes and reactions in CVD. The figure is reproduced after an original figure in [8]. 
Activation of these reactions occurs when sufficient energy is provided to the system. Such energy can, for instance, be in form of heat (thermal CVD), plasma (plasma-enhanced/assisted CVD), or radiation (e.g., photo-assisted CVD). Furthermore, film growth by CVD can be affected by different parameters, such as properties and temperature of the substrate, operation pressure and chemistry of the precursors $[6,8]$.

\subsection{Forms of CVD}

There are a variety of different forms of CVD that can be used to for material processing. What differs them is mainly how the chemical reactions are initiated, and the nature of these reactions, i.e., if it is a gas-phase reaction, surface reaction, or both. Chemical reactions in CVD are initiated by supplying energy to the process $[6,9-11]$ :

- Thermal energy (heat) - where high temperatures are provided to the process (e.g., hot wall and cold wall CVD). This type of CVD is one of most used and straight forward type.

- $\quad$ Electric energy - where plasmas are used, i.e., plasma-enhanced CVD (PECVD). This type of CVD is described in more details in Section 2.2 (Plasma-Enhanced Chemical Vapor Deposition).

- Radiation energy - where high energy photons are used, i.e., photo-assisted CVD. There are two types of photo CVD: photothermal, where the substrate is heated locally by a laser beam for selective growth; and photolytic, where a light source, e.g., a laser or UV light, is used to decompose the precursors.

- Energy from a hot filament - where a hot wire/filament (HFCVD, also known as catalytic-CVD) is used to decompose the precursors, resulting in radical molecules formation.

In several CVD types, the chemical reactions take place in the gas phase and on the substrate surface simultaneously, which complexifies the CVD processes, and usually lead to film conformality loss. A solution to such problems is a form of CVD where the gas phase precursors are introduced to the system separately which eliminate the gas phase reactions. This form of CVD is called atomic layer deposition (ALD). ALD consists of a sequence of so-called cycles, 
where precursors are pulsed into the system individually and separated by purging steps [12, 13]. The ALD cycle can then be repeated until desired film thickness is reached, an ALD cycle is schematically shown in Fig. 2.2.

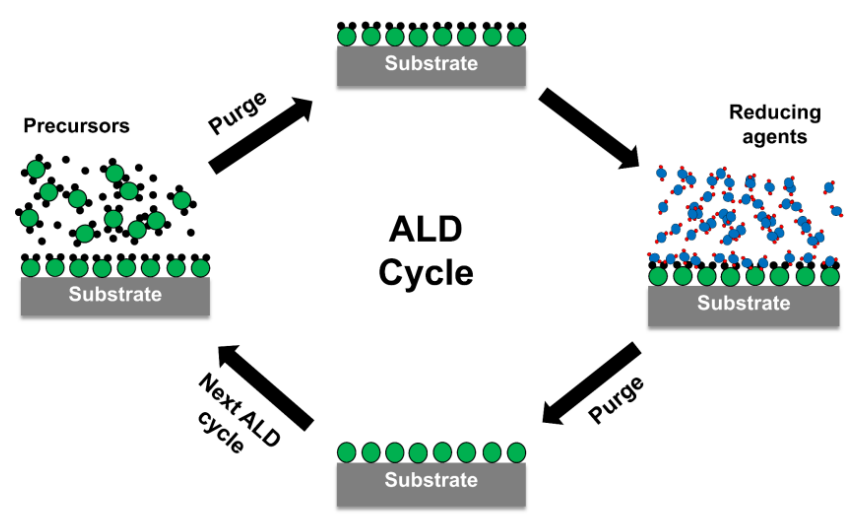

FIGURE 2.2. A schematic of an ALD cycle.

Precursor molecules, containing the material in desired, react chemically with the surface-active sites and become partially dissociated. When the surface is saturated, i.e., "most" of the active sites are occupied, the process self-terminates. A purging step/pulse, usually an inert gas, follows to remove the unreacted excess molecules and the dissociated fragments from the system. In the next step, other precursor molecules (also known as reducing agents, co-reagents, or co-reactants) are introduced where they chemically interact with the undissociated fragments of the first precursor molecules and form by-product species, leaving only the material in desire to form a "monolayer" on the surface, i.e., a thin film. The by-products are then removed from the system by another purging step with an inert gas.

Reducing agents in ALD can be molecular and/or in form of active species created by using plasmas, i.e., plasma-enhance ALD (PEALD). Each ALD cycle results in an exact film thickness, therefore, grow rate in ALD is usually referred to growth per cycle (GPC). ALD can be used to deposit a wide range of materials, such as oxides, nitrides, and pure metals (copper, gold, platinum, etc.) [14]. Since the deposition is controlled by the number of active sites on the surface rather than the amount of precursor in the system, i.e., self-limiting, ALD can produce continuous films with precise thickness and exceptional conformality and uniformity on complex surfaces and structures including trenches and vias with high-aspect ratio. Another 
advantage of ALD is that the deposition is performed at much lower temperatures, compare to thermal CVD. Because film growth relies on the growth of the film at each cycle, and each cycle includes different pulses with different times, the deposition rate in ALD is slow, which is the main drawback of ALD. Nevertheless, ALD is an excellent method for depositing very thin films in many areas, especially in electronic applications.

Moreover, regardless the source of energy or the nature of the chemical reactions, CVD, or ALD, can operate at different pressures, e.g., atmospheric pressures (APCVD, APALD), low pressures (LPCVD, LPALD), ultrahigh vacuum (UHVCVD, UHVALD) [6, 9-11].

\subsection{Plasma-Enhanced Chemical Vapor Deposition}

\subsubsection{Plasma Basics}

Plasmas can be described as the fourth state of matter, along with solids, liquids, and gases. The general definition of a plasma is an ionized gas that contains a mixture of freely moving charged particles (electrons and ions) that is in average electrically neutral [15]. Some plasmas, such as the process plasmas investigated in this thesis, also contains neutral species (i.e., not fully ionized). When an atom, or molecule, is subjected to sufficient energy, excitation of one, or several, of the electrons occurs. If this energy is above the ionization potential of the atom/molecule it leads to the release of electrons resulting in free, randomly moving electrons and ions. Depending on the discharge conditions there are two types of plasmas: thermal (hot) plasmas (e.g., stars in our universe), where the collision rate between electrons and gas molecules is high enough to establish an equilibrium in energy between the electrons and ions. This often involves close to complete ionization of the gas molecules. There are also non-thermal (cold) plasmas, where the gas molecules are not completely ionized, and do not establish an equilibrium in energy between the electrons and ions. In this case, the high-energy particles are mostly composed of electrons. Here, it is often stated that the electron temperature is much greater than the ion temperature. The electron temperature, i.e., electron energy, is usually measured in electron volt $(\mathrm{eV})$, which is the energy that an electron has gained in vacuum when accelerating across one volt of electric potential $(1 \mathrm{eV}=11600 \mathrm{~K})$ [16]. Glow discharges, studied in this thesis, belong to the non-thermal plasmas. These plasma discharges 
are generated using an electric field (a voltage applied between two electrodes). Examples of such plasmas are fluorescent light bulbs and neon lighting.

The overall charge neutrality of a plasma is commonly referred to as quasi-neutrality. The reason is that at smaller scales the distribution of positive and negative charge is unbalanced, which gives rise to charged regions and electric fields. Therefore, to better define plasma discharges it often resorts to the following three conditions [15, 17]:

- The plasma physical dimensions must be much larger than the Debye length. The simplest definition of Debye length is the distance over which ions and electrons can be separated in a plasma (i.e., charge imbalance). In the case of our processing plasmas the Debye length usually amounts to at least a few tens of $\mu \mathrm{m}$. This means that the interactions in the plasma bulk are more important than the interactions at the edges of the plasma.

- The number of particles inside the Debye sphere (where the radius = Debye length) is much larger than unity.

- The electron plasma frequency, i.e., the oscillations of the electrons, is higher than the electron-neutral collision frequency.

An effect of a plasma is the formation of so-called plasma sheaths. The only place where the quasi-neutrality can be violated is in the sheath between the plasma and another boundary, such as the walls of the deposition system. The plasma sheath plays an essential role in material processing because it is the part of the plasma that interacts with the surface of the substrate. The potential of a wall and/or substrate is commonly negative relative to the plasma since electrons move faster than the ions and therefore leave the plasma to a greater extent. This process continuous until a large enough potential difference between the plasma and the walls has been built up resulting in a negative, repelling sheath drop. In this way the loss rate of electrons and ions reaches equilibrium. The plasma potential is often positive (usually a couple of volts) relative the grounded walls. The same does also apply to a grounded substrate [15, 17]. 


\subsubsection{Plasma in CVD}

Plasmas can be utilized in various approaches in material processing. They can be used in material etching and cleaning, implantation, surface modification, and especially in plasma-assisted deposition. Plasma-assisted deposition is widely used in material processing and especially in manufacturing of electronic devices. Such devices are usually sensitive to temperatures, therefore high temperature deposition methods of films, such as thermal CVD, is unsuitable. Due to the high reactivity of the plasma species at low temperatures, films can be deposited at low temperatures without compromising the film quality.

Plasma-assisted depositions can be divided into two operation modes: non-reactive with inert gas, where plasma is used to sputter atoms from a target material which is deposited on a substrate, e.g., sputtering deposition in physical vapor deposition (PVD); and reactive mode, where the plasma species are chemically involved in the film deposition, e.g., plasma-enhanced chemical vapor deposition (PECVD, also referred to plasma-assisted chemical vapor deposition PACVD) [15], and reactive sputtering deposition in PVD [18].

PECVD is a CVD method where a non-equilibrium and non-thermal plasma is used as a source of energy instead of heat as in thermal CVD. The plasma is used to generate chemically active species and to modify the surface reactions. When plasma particles and photons, mainly electrons, with sufficient energy inelastically collide with the precursor molecules/atoms in the gas phase, they break the chemical bonds in the precursor producing reactive species, including radicals and ions. Since the electron energy required to form the reactive species is low enough and is usually higher than the surface energy, films can be deposited at lower temperature, compare to thermal CVD. For instance, $\mathrm{SiO}_{2}$ can be deposited using $\mathrm{SiH}_{4} / \mathrm{O}_{2}$ at $100-300{ }^{\circ} \mathrm{C}$ using PECVD, compare to $600-800{ }^{\circ} \mathrm{C}$ using thermal CVD [15]. Moreover, the plasma ions can be used for surface modification by providing energy to the surface, which enhance surface activities by, e.g., nucleation, ligand removal, and atom migration. Surface modification does not only aids film deposition, but it also modifies the film properties such as composition and morphology. In addition, broader selection of precursors can be used in PECVD [6, 9].

Understanding plasma is a difficult subject and becomes very complex when used in PECVD, mainly due to the many different gas phase and surface chemical reactions (Fig. 2.3), and the physical effects of the plasma in PECVD [19-21]. 


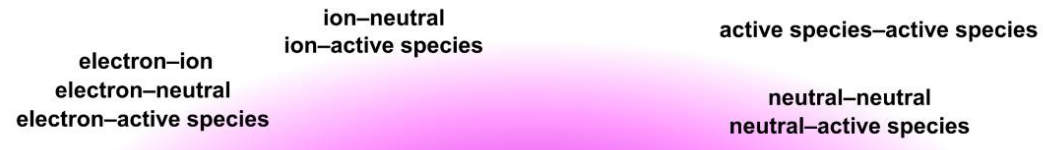

\section{Plasma}

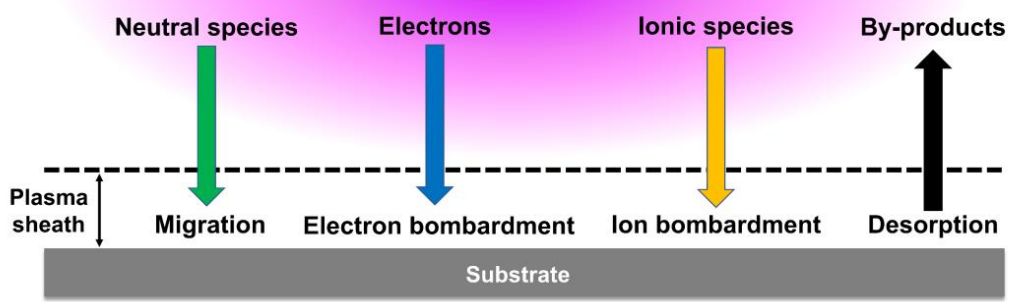

FIGURE 2.3. A schematic of the different processes and possible chemical interactions in PECVD [9]. The figure is modified with an inspiration from [22].

A common issue in PECVD is film conformality, which is mainly due to the high gas phase reactions and film growth rate. An approach to control the conformality of the film is to use plasma-enhanced atomic layer deposition (ALD), where the plasma is applied in pulses and is used as a co-reactant. However, thorough control of the deposition process is required in both PECVD and PEALD, which is a difficult task [15]. Furthermore, surface bombardment by plasma ions can enhance the surface reactions, however it can also cause film stress, unwanted film crystallinity modification and ion implantation. Ions with enough energies can cause film etching and/or degradation, such effects can however be controlled by applying a substrate bias voltage.

Applying bias voltage to the substrate is usually done to control the effect of the charged plasma species, and charged chemically reactive species, on the substrate by controlling their kinetic energies. Applying a negative bias will accelerate the ions towards the substrate, which can be utilized to improve surface reactions. A positive bias, on the other hand, causes electron attraction to the substrate, which can be utilized, for instance, to create dangling bonds on the surface to increase film quality and growth rate. Moreover, attracting plasma electrons to the substrate surface can also cause electron-precursor surface reactions which can be used for metal film deposition at even lower temperatures. Such approach allowed for the development of a new low temperature PECVD method, which this thesis is based on. More details can be found in Paper I of this thesis. 


\subsubsection{Plasma CVD Reactors}

Conventional CVD systems have several basic components, that is: a vacuum chamber; a pumping system; a temperature control system; and a control system for the precursor flow. Plasma CVD reactors have basically the same components as conventional CVD system with an additional component, i.e., a plasma discharge system. There are different types of PECVD reactors: radical-enhanced plasma reactors; direct plasma reactors; and remote plasma reactors. These reactors have different configurations, depending on how the plasma interacts and affect the substrate surface [23].

In radical-enhanced plasma reactors, the substrate is located at a remote position with a large distance to the plasma. The large distance contributes to the recombination of the plasma electrons and ions, hence reducing the densities of these particles significantly at the substrate surface. The large distance also reduces the radical species, allowing only small amounts to reach the substrate surface. Hence, longer deposition time is required [23, 24].

In direct plasma reactors, the substrate is directly positioned in contact with the active plasma. The plasma is generated between two parallel electrodes, where one of the electrodes is powered with a radiofrequency (RF) signal and the other electrode is grounded. Such configuration is called capacitively-coupled plasma. In this configuration, usually the substrate is placed on the grounded electrode and is involved in the plasma generation, which results in high flux of plasma species, radicals, and reactive species towards the substrate. The high flux of plasma species, including ions and electrons, can however cause unwanted substrate surface modifications, such as defects and pinholes, due to, e.g., particle bombardment. Moreover, since the substrate is involved in plasma generation, many different reactive species are produced simultaneously which makes the overall reactions very complex. It also makes the controlling of plasma and substrate properties difficult $[6,9,23,24]$.

In remote plasma reactors, the substrate is not in contact with the active plasma. The plasma and the substrate position are spatially separated so that the substrate is not involved in the plasma generation. The substrate is usually in contact with the so-called plasma afterglow region, where the electrons in this region do not have enough energy to cause ionization. Such configuration allows high flux of radicals and active species towards the substrate and reduces plasma particle bombardment of the substrate surface, which minimizes the unwanted surface modification issue. In addition, optimizing deposition properties is relatively easy compare to direct plasma reactors. Different plasma sources can be used in remote plasma: microwave 
plasma; RF-driven inductively-coupled plasma (ICP); electron cyclotron resonance plasma (ECR); and hollow cathode plasma [6, 9, 23, 24].

\subsubsection{Hollow Cathode Plasma}

A remote plasma CVD reactor with hollow cathode configuration has been the foundation for the work in this thesis. Hollow cathode plasma systems have been used widely in many material processing applications, including film synthesis by CVD, due to the plasma properties, the operation and design simplicity [25]. Hollow cathode sources can produce plasmas with high electron density in the range of $10^{18}-10^{19} \mathrm{~m}^{-3}$ [26]. Because hollow cathode plasma sources can generate plasmas with high densities, it was chosen as the plasma source in CVD configuration developed in this work.

As mentioned before, a plasma can be generated by applying a voltage between two electrodes, a cathode and an anode, which cause electron-gas interactions that lead to the gas ionization. In the hollow cathode system, the cathode contains a cavity. At the boundaries of the cavity, plasma sheaths are created. This entraps the electrons and forces them to oscillate between the boundaries of the cavity, a phenomenon that is referred to as the "pendulum effect". The oscillation of the electrons increases the probability for inelastic electron collisions with the gas atoms, hence increasing the ionization which provides a higher plasma density. Hollow cathodes come in different geometries: tube, cylindrical, spiral, and parallel plate. They can be powered using a DC voltage, pulsed DC, or by radiofrequency power supply [25, 27].

Electrons play an important role in the deposition process of the newly developed CVD method, where they are used as reducing agents in an electron-precursor surface chemistry reaction. Therefore, the free plasma electrons are attracted to the substrate holder, by applying a positive substrate DC bias $(0-80 \mathrm{~V})$, for precursor-electron surface reactions. More details on the method and the system can be found in Paper I. The plasma system used in this work (Fig. 2.4) was a cylindrical-shaped hollow cathode with a stainless-steel tube and an insert. Since only the electrons are important in this case, titanium is used as the insert material, due to its low sputter yield [28]. Ar gas is fed, with a flow of 50-70 sccm, into the upstream end of the cathode cavity where it becomes ionized as it travels downstream. A DC power supply, with a power in the range of 5-150 W, was used to generate the plasma. The hollow cathode plasma system was cooled by water. 
(a)

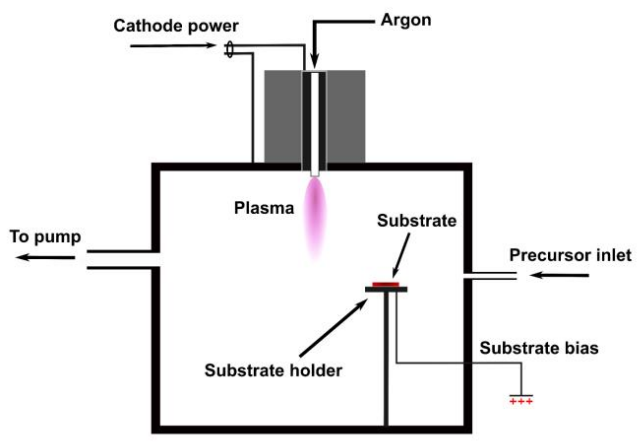

(b)

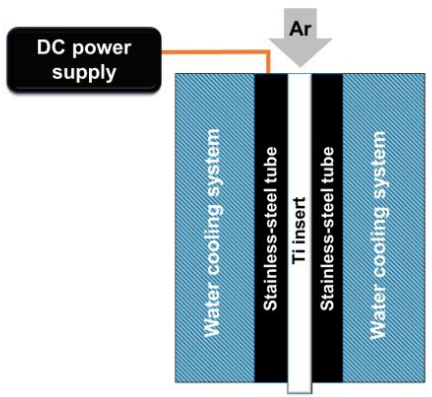

FIGURE 2.4. Schematics of (a) the experimental setup and (b) the hollow cathode plasma system used in the newly developed CVD method.

An estimate values of the electron current drawn from the plasma, through the substrate holder and to the substrate bias supply, could be measured using a current clamp placed outside the reactor chamber. Figure 2.5 shows the plasma cathode current, and the current drawn from the plasma through substrate holder. An electron saturation current region is obtained when a substrate bias was applied in the range of $10-80 \mathrm{~V}$ (DC). In this region, $97 \%$ of the plasma cathode current is drawn through the substrate holder.

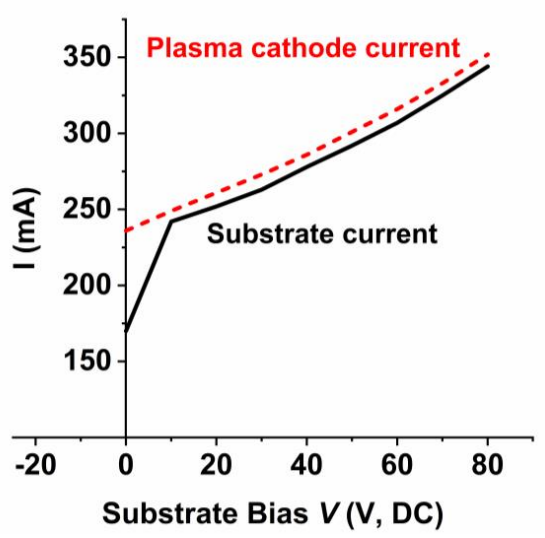

FIGURE 2.5. Current-voltage (IV) curve for a $70 \mathrm{~W}$ Ar plasma where the dashed red line shows the plasma current of the plasma power supply and the solid black line shows the current drawn through the substrate holder at different substrate biases, which correspond to $97 \%$ of the plasma current when a substrate bias of $\geq 10 \mathrm{~V}$ is applied. 


\subsection{Precursors in CVD}

Precursors in CVD are molecules that contain the desired atoms, for the material to be deposited as a film. The desired atom is typically the central atom in such molecule and is bonded to molecular fragments called ligands to form a complex. The purpose of the ligands is to give the precursors the properties required for a certain CVD process, e.g., thermal stability, volatility, activity, etc.

There are some common requirements that CVD precursors need to meet. In general, the precursor should be: volatile, of high purity, thermally stable during transport into the reaction chamber; have higher decomposition temperature than evaporation temperature; have good compatibility/affinity with co-precursors during film growth; the decomposition should be clean without unwanted by-products that might be incorporated in the film; and the precursors should be non-hazardous and produced at low costs $[6,29]$. Depending on the nature of the deposition process, these requirements can be differed and modified. In addition, different forms of CVD have additional precursor requirements. For instance, in thermal CVD the precursor molecules are preferred to have bulky complex structures which decrease the precursor's sensitivity to air/moisture, whereas ALD (where all reactions take place on the surface of the substrate) require precursors with smaller and less bulky ligands to minimize the steric hindrance effect [6].

This thesis has focused on CVD of Fe, $\mathrm{Ni}$ and Co. Iron, cobalt, and nickel precursors, used in CVD and ALD, can be divided into different classes, depending on the metal-ligand bonding: carbonyls, cyclopentadienyls, alkoxides, $\beta$-diketonates, and amidinates [30-32]. Generally, the type of metal-ligand bond allows these precursor complexes to exhibit different properties with different advantages and disadvantages. For instance, the metal-nitrogen bonds in amidinates precursors make them more reactive than metal-oxygen and metal-carbon based precursors. This is because the metal-nitrogen bonds are easier to break than metal-oxygen and metal-carbon bonds.

Carbonyls precursors (e.g., iron(0)pentacarbonyl, Fig. 2.6) have high volatility with good deposition rate, however it suffers from safety issues due to its toxicity (decomposes into $\mathrm{CO}$ ) and flammability [31]. $\beta$-diketonate, and alkoxides, precursors (e.g., iron(III)-, cobalt(III)-, and nickel(II) acetylacetonate, Fig. 2.6) have the advantage of thermal stability and relatively low reactivity, which makes them easier to handle. However, these precursors contain metal-oxygen 
bonds which usually used to deposit metal oxide films, and they can leave $\mathrm{C}$ and $\mathrm{H}$ in the film [33]. Also, $\beta$-diketonates have bulky structures that increase the steric hindrance effect (the reason for the low reactivity) which leads to low growth rate.
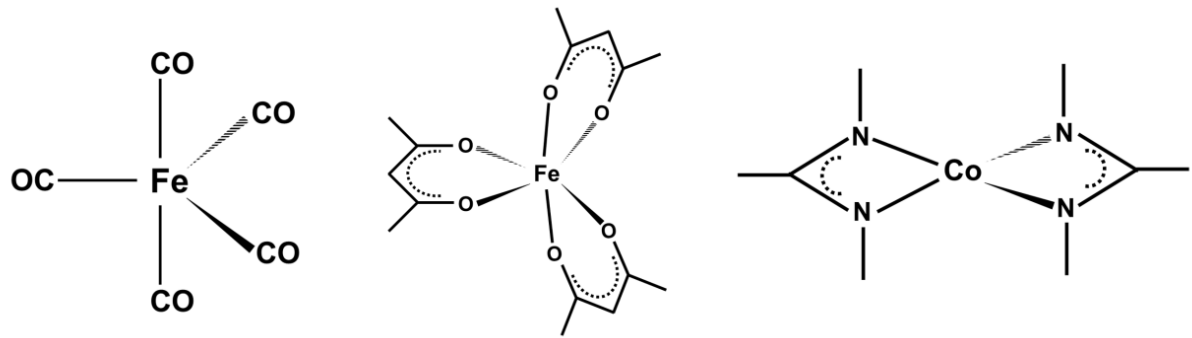

FIGURE 2.6. Precursor structure of iron(0)pentacarbonyl (left), iron(III)acetylacetonate (middle), and cobalt amidinate (right).

Amidinate precursors (e.g., nickel amidinate and cobalt amidinate, Fig. 2.6) are volatile, thermally stable, and highly reactive (due to the metal-nitrogen bonds). The volatility can be tuned by altering the ligands side group(s). In addition, amidinate precursors do not have metal-oxygen nor metal-carbon bonds, facilitating the deposition of pure metals with low carbon impurities. The use of metal amidinate precursors in CVD is relatively new and research on these precursors is in progress. Although, promising results have been reported of depositing pure metals (and metal oxides) using these precursors [34, 35].

Cyclopentadienyls precursors, such as metallocene (Fig. 2.7), are oxygen-free, thermally stable, volatile, widely available, and have previously been used in CVD and ALD [36-42]. Films deposited with metallocene, however, may contain carbon impurities and higher deposition temperatures might be needed to obtain film crystallinity $[31,43]$.

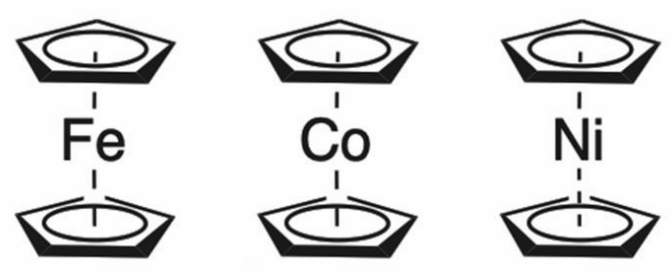

FIGURE 2.7. Ferrocene (left), cobaltocene (middle), and nickelocene (right) precursors. 
Metallocene precursors (bis(cyclopentadienyl)M(II), $\left(\mathrm{MCp}_{2}\right)$, where $\mathrm{M}=\mathrm{Fe}, \mathrm{Co}$, and $\mathrm{Ni}$ ), are used as the metal source in the work of this thesis. The sublimation temperatures of ferrocene, cobaltocene, and nickelocene (Fig. 2.7) were examined, using a vacuum Schlenk line system at $50 \mathrm{~Pa}$ and a heating oil bath, and determined to 70,100 , and $70{ }^{\circ} \mathrm{C}$, respectively. These temperatures were then used to sublime the precursors at a pressure of $50 \mathrm{~Pa}$ in a custom-made stainless-steel bubbler. More details can be found in Paper I of this thesis.

\subsection{CVD of Fe, Co, and Ni}

Iron, cobalt, and nickel are metals belong to the first-row transition metals ( $\mathrm{Ti}, \mathrm{V}, \mathrm{Cr}, \mathrm{Mn}, \mathrm{Fe}$, $\mathrm{Co}, \mathrm{Ni}$, and $\mathrm{Cu}$ ) that are important in many areas due to their properties. TAB. 2.1 shows a few properties of these metals [44]. For instance, iron oxides have been reported to be used in catalytic applications due to their high catalytic activity [45-47]. Due to the electrical and magnetic properties of iron, cobalt, and nickel, these metals are used in many electronic and magnetic applications [48-56]. For instance, $\mathrm{Co}\left(\mathrm{CoSi}_{2}\right)$ can be used as contact material in metal-oxide semiconductors (CMOS), also $\mathrm{Co}$ and $\mathrm{Ni}$ can be used as magnetic tunnel junctions (MTJ) in magnetic memory devices [30].

TABLE 2.1. A few properties of Fe, Co, and Ni [44].

\begin{tabular}{|c|c|c|c|c|}
\hline Metal & $\begin{array}{c}\text { Resistivity } \\
(\mathbf{\Omega} \mathbf{m})\end{array}$ & $\begin{array}{c}\text { Density } \\
\left(\mathbf{g} / \mathbf{c m}^{\mathbf{3}}\right)\end{array}$ & $\begin{array}{c}\text { Standard reduction } \\
\text { potential, } \boldsymbol{E}^{\circ},(\mathbf{V})\end{array}$ & $\begin{array}{c}\text { Structure } \\
(\text { At Room Temperature) }\end{array}$ \\
\hline $\mathrm{Fe}$ & $9.6 \cdot 10^{-8}$ & 7.87 & -0.45 & $\mathrm{BCC}$ \\
\hline $\mathrm{Co}$ & $6.2 \cdot 10^{-8}$ & 8.86 & -0.28 & $\mathrm{HCP}$ \\
\hline $\mathrm{Ni}$ & $6.9 \cdot 10^{-8}$ & 8.90 & -0.26 & $\mathrm{HCP}$ \\
\hline
\end{tabular}

Most of the first-row transition metals have negative standard reduction potentials, $E^{\circ}$, (Fig. 2.8) which means that the reduction of these metals in CVD from a positive oxidation state, in their precursors, to metals are difficult (the free energy, $\Delta G^{\circ}$, of the reaction becomes positive, i.e., non-spontaneous, according to $\Delta G^{\circ}=-n F E^{\circ}$, where $n$ is the number of electrons transferred in the reaction and $F$ is the Faraday constant [57]). Therefore, depositing these metals in CVD requires either high temperatures or powerful reducing agents. In addition, the 
deposition of these metals with high purity, especially iron, are challenging due to their high tendency to form oxides.

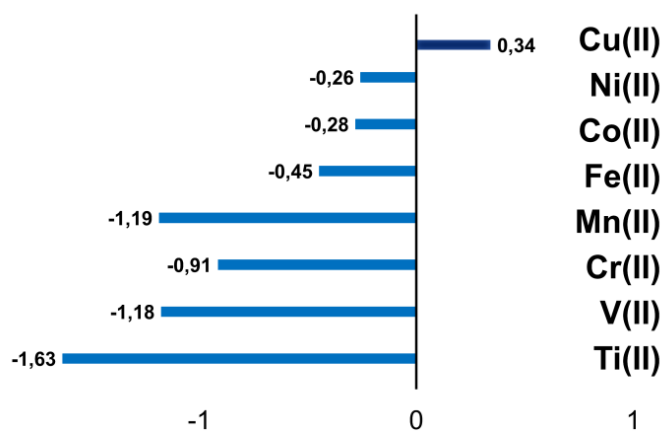

Standard Reduction Potential, $E^{\circ}(\mathrm{V})$

FIGURE 2.8. The standard reduction potential of first-row transition metals [32].

CVD of iron, iron oxide, cobalt, and cobalt oxide films have been reported to be deposited using different precursors and co-reactants at temperatures ranging from $300{ }^{\circ} \mathrm{C}$ to $800{ }^{\circ} \mathrm{C}[31,58-$ 63]. Cobalt can also be deposited by precursor decomposition at temperatures as low as $50{ }^{\circ} \mathrm{C}$, however undesirable reactions, such as precursor polymerization and formation of unstable products, can compete with the deposition of pure Co [64-66]. Moreover, CVD of nickel films have been deposited at temperatures in the range of $160-250^{\circ} \mathrm{C}[42,67]$. An approach to reduce the deposition temperatures of these metals is to apply plasma as source of energy, i.e., PECVD. For instance, PECVD of iron and cobalt films have been reported at temperatures of 100 and $70{ }^{\circ} \mathrm{C}$, respectively $[68,69]$.

Due to the conformality issue, the generally high operation temperature of CVD, and the requirement of uniform thin films that can be deposited on complex structures and on high aspect ratio features in many applications, CVD of these metals are less applicable. To address these issues and to meet such requirements, thermal ALD and PEALD can be used. For instance, iron oxide films can be deposited at temperatures ranging from $150{ }^{\circ} \mathrm{C}$ to $500{ }^{\circ} \mathrm{C}$ by thermal ALD [36-38, 70-72], and by PEALD [73]. Cobalt and nickel films can be deposited at temperatures ranging from $125^{\circ} \mathrm{C}$ to $350{ }^{\circ} \mathrm{C}$ by thermal ALD [41, 74-78], and PEALD [39, 79-81]. However, issues such as precursor decomposition (i.e., CVD growth) and the loss of the characteristic self-limiting component of ALD, have been reported in many of these processes. 
The major issues with ALD are the low growth rate and, as mentioned before, the lack of powerful reducing agents for first-row transition metals [32]. For instance, cobalt and nickel metal films have been reported to be deposited by thermal ALD using powerful reducing agents at $170-180{ }^{\circ} \mathrm{C}$ [82]. However, such powerful reducing agents are only demonstrated at a laboratory scale. Therefore, reducing agents of these metals require developments in precursor design and a great understanding of the growth mechanism of these metals.

The basic operation of a reducing agent is to transfer electrons to the metal ions in the precursor molecule, reducing it to metal with zero oxidation state. In this thesis, I identify an alternative source of electrons, i.e., free plasma electrons, and show that they can be used to reduce metal ions to deposit metallic thin films without using molecular reducing agents. In simpler words, the free plasma electrons are used as powerful reducing agents. Herein, I introduce a new CVD method where the plasma electrons are attracted to the substrate by using a positive substrate bias voltage and a conductive substrate, allowing electrons to interact directly with the metal precursors in a surface redox chemistry (Fig. 2.9).

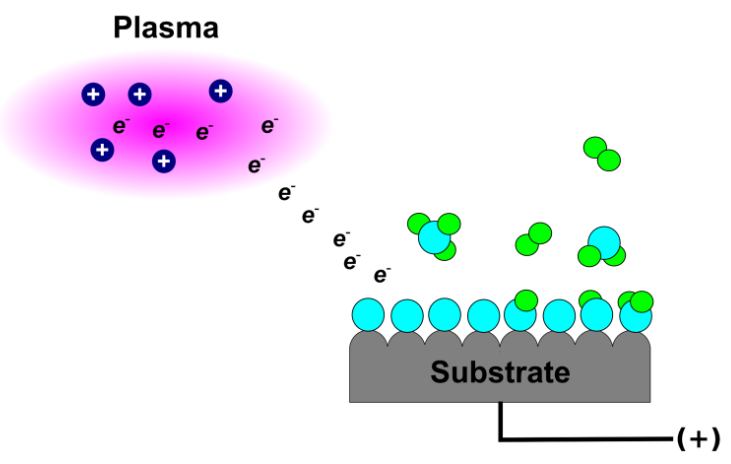

FIGURE 2.9. A Schematic of the deposition process in the newly developed CVD method.

The newly developed method has shown its ability to deposit iron, cobalt, and nickel from there metallocene, on silver substrates at temperatures in the range of $35-50{ }^{\circ} \mathrm{C}$. More details in Paper I. Since the plasma electron properties (electron temperature and density) can be modified, I believe that the new CVD method can be used to deposit other transition metals, such Mn, Ti, Ag and Ru. 


\section{Area Selective CVD}

Area selective deposition (ASD) is a process where a desired film is deposited on region(s) of a surface and not on others. In other words, the ability of depositing films on specifically selected areas of a pattered surface of a substrate. ASD allows film deposition in a broad range of important fields, especially in micro/nanoscale electronics and catalysis applications [8386].

On way to make a pattered film is by using photolithography which is a process of transferring features and shapes from a template to the surface using light. Photolithography usually includes the use of a material that is photosensitive (photoresist) and a patterned mask to define the regions where the film is not desired. A continuous film is first deposited on all areas of the surface followed by applying a photoresist over the whole film. A patterned mask then allows only some regions of the photoresist to be exposed to UV light. This causes a chemical change in the photoresist that is exposed to the UV light by the mask. In positive photoresist (a commonly used method), the exposed areas of the photoresist are chemically removed (in negative photoresist, the unexposed areas of the photoresist are removed) and a pattern is created. The patterned is then transferred into the film by chemical etching, etching only the areas not covered by the patterned photoresist. The process can be repeated with different patterns and materials to build many layers until desired structures are achieved $[87,88]$. Such an approach is called top-down pattering.

Photolithography is a reliable and robust method. However, due to the continuous miniaturization in electronic device, issues such as high cost, multiple step processes and process complexity, start to arise in photolithography. Hence, bottom-up patterning, enabled by ASD, is preferred as dimensions shrinks. In ASD, the selectivity is achieved by modifying the reactants (precursors) and/or the reaction surfaces to control the film growth on desired regions of the substrate $[85,86]$.

ASD in CVD is usually achieved by changing the surface chemistry of either the growth area or the non-growth area of the surface, to control the adsorption/reaction of precursor molecules to only a specific area on the substrate. The general theory is, when reactants reach a surface, due to kinetic and thermodynamic driving forces, the reactants have some probability to physisorbed on the surface, diffuse on the surface, interact with other reactants and with surface, and eventually becomes chemisorbed to form stable nuclei where film nucleation initiates. The 
formation of stable nuclei is determined by the adsorption energies of the reactants and the interaction energies between the reactants. In correlation, these energies are affected by different substrates, i.e., the adsorption energies of the reactants as well the interaction energies between them varies on different substrates. Therefore, formation of stable nuclei on one substrate and not on another is determined by the substrate surface material, allowing selective deposition.

Different methods have been reported to enable ASD in CVD, and the basic idee of these methods is to enhance, or inhibit, film growth selectively utilizing the different growth on different surfaces. Areas on the surface of the substrate can be activated using a catalytic reactant, electrons, or ion bombardment [89-91], allowing film growth only on the activated areas but not on the non-activated ones. Areas on the surface of the substrate can also be passivated using polymer films or self-assembled monolayers of organic molecules (SAMs) [92-94], which are often used to block areas of the surface where film growth is undesired. Figure 3.1 shows a schematic of an area selective deposition where blocking agents are selectively adsorbed on the non-growth areas to block film growth on these areas. Film nucleation can also be inhibited on certain areas on the surface by passivating these areas by ion implantation [95] or by inhibitors such as aniline, fluorine, hydrogen, or ammonia [96-98]. Selectivity can also be afforded by utilizing different film growth or nucleation rates on different materials on the substrate [99], which can be further enhanced by adding etching steps to the deposition process [100]. Blocking areas of the substrate can also be achieved by applying a layer of masking materials such as polymers, which offers an inexpensive and simple way to achieve selective deposition on macro and micro/nanoscale dimensions [101, 102].

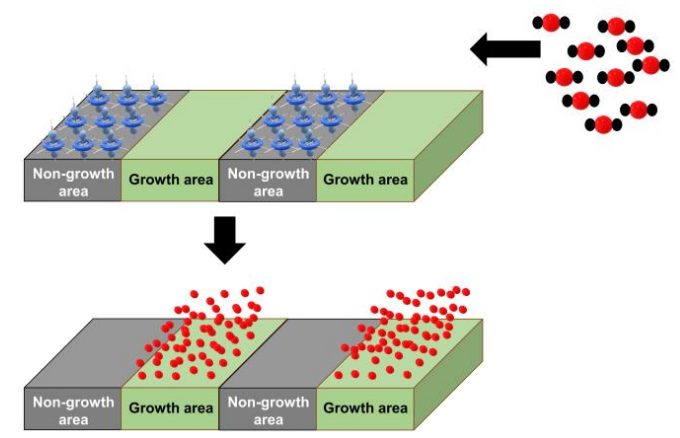

FIGURE 3.1. A schematic of an area selective deposition where blocking agents are selectively adsorbed on the non-growth areas to block film growth on these areas, allowing film growth only on the growth areas. 
ASD of thin film using CVD for electronic applications have gained a lot of attention lately due to material advancement, and feature size and structure complexity. ASD by thermal CVD offer fast, pure, and high dense films due to the high operation temperatures in CVD (400-1200 $\left.{ }^{\circ} \mathrm{C}\right)$. The deposition temperatures, among other parameters in CVD, control the chemical reactions on the surface. Since surface reactions can vary on different surfaces, temperature can be utilized to control kinetics and thermodynamics to be more favorable for nuclei formation and film growth on one substrate but and not on others, i.e., selective growth. In addition, the nucleation rate and the film growth rate are also determined by the surface chemistry, hence also controlled by temperature, allowing film growth to be faster, or slower, on desired areas, or undesired areas, of the surface $[86,103]$.

However, limitations using ASD in thermal CVD start to arise where high temperatures are not applicable. For instance, high temperatures lead to metal diffusion and degradation in transistors and interconnects which are usually made of complex and thin metal films [86]. Attempts have been made to lower the temperature for ASD in CVD by redesigning precursors than can be used at lower temperatures without changing the selectivity process [104]. An alternative for thermal CVD is PECVD where ASD can be applied at lower temperatures $\left(<400{ }^{\circ} \mathrm{C}\right)[105-$ 107]. Moreover, since ALD usually operates at lower temperatures than CVD and the precursors are separately delivered during deposition, ALD is an excellent approach for ASD, where the growth on certain areas of the substrate can be controlled by modifying the surface chemistry, hence allowing for more flexibility in the processing [85].

\subsection{ASD of Fe, Co, and Ni}

Up to date, there are a few reported processes/studies in area selective CVD and ALD of first row-transition metals. This is because these metals are usually very challenging to deposit (see Section 2.4, CVD of Fe, Co, and Ni). For iron, cobalt, and nickel, different approaches have been used to achieve ASD of these metals [108-113]. For instance, iron oxide and nickel oxides are selectively deposited on noble metals by catalytically activating the surface with oxygen [89]. Also, cobalt and nickel films are selectively deposited on several substrates, utilizing the different film growth rate on these substrates $[114,115]$. However, for many of these approaches, and as mentioned before, either high temperatures are used, or powerful reducing agents are required. Therefore, advancements in these areas are essential. 
From the work done in Paper I, the requirement of a low electrically resistive substrate in the newly developed CVD method, where plasma electrons are used as reducing agents, has provided us with an idea to achieve ASD of metal-on-metal deposition. That is, depositing films on substrates with different electrical resistivity, i.e., substrate with high and low resistive materials. This has been investigated by depositing iron films, from ferrocene, on high resistive $\mathrm{SiO}_{2}(300 \mathrm{~nm})$ substrates that are partially coated with low resistive $\mathrm{Ag}(40 \mathrm{~nm})$. Both parts of the substrate were biased with $+40 \mathrm{~V}$, Fig. 3.2. The deposition temperature was $40^{\circ} \mathrm{C}$ and the deposition time was $60 \mathrm{~s}$.

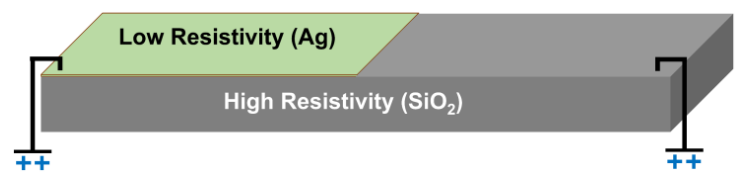

FIGURE 3.2. A schematic of the substrate used for iron film deposition where the electrical resistivity of the substrate is utilized to achieve ASD.

The results show that approximately $300 \mathrm{~nm}$ of iron film is deposited on the low resistive Ag area of the substrate, whereas no, or insignificant, iron film could be detected on the high resistive $\mathrm{SiO}_{2}$ area. Figure 3.3 shows a schematic of the deposition process.

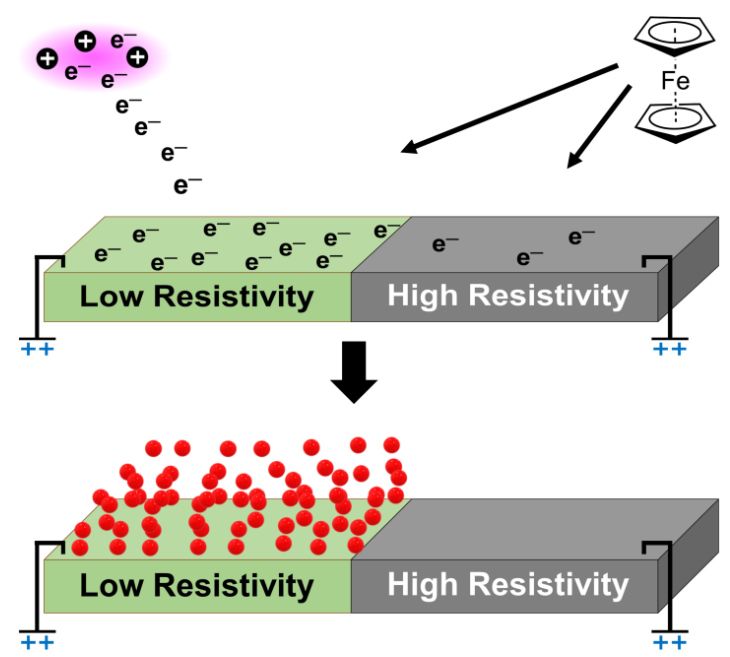

FIGURE 3.3. A schematic of the deposition process used for iron film deposition where the electrical resistivity of the substrate is utilized to achieve ASD in the newly developed CVD method. 
Figure 3.4 shows the top view scanning electrons images (SEM) with elemental mapping by energy dispersive X-ray spectroscopy (EDS) of film deposited on both areas of the substrate. More details can be found in Paper II of this thesis. The results indicate that such approach is inherently ASD that does not rely on any thermodynamic or kinetic factors to achieve selectivity.
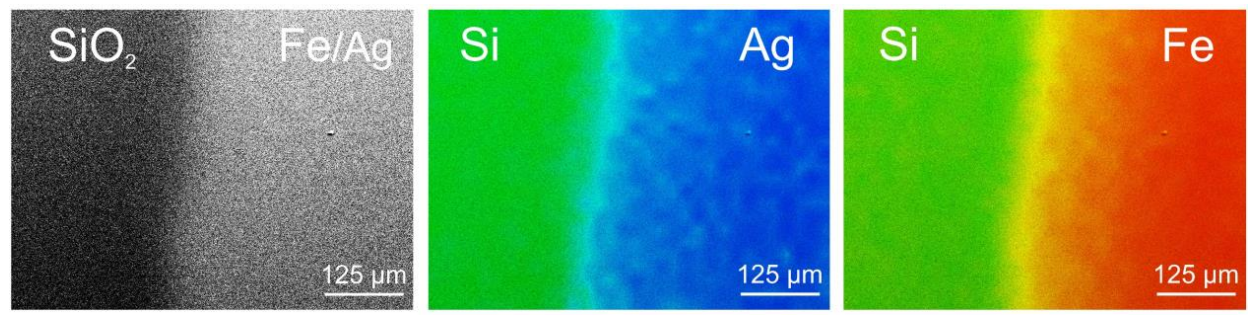

FIGURE 3.4. Top view scanning electrons images (SEM) with elemental mapping by energy dispersive X-ray spectroscopy (EDS) of the interface region between the Ag coated and bare $\mathrm{SiO}_{2}$ surface region. EDS mapping shows that the $\mathrm{Fe}$ is deposited only on the Ag coated surface region.

Additionally, the deposition temperatures of the new CVD method were in the range of 35-50 ${ }^{\circ} \mathrm{C}$. Such low deposition temperatures allow temperature sensitive materials to be applied in the deposition process. This led to the study of temperature sensitive materials to be used as masking materials to achieve ASD, by blocking precursor adsorption on the masked area. This has been investigated by depositing iron films, from ferrocene, on $\mathrm{Ag}(40 \mathrm{~nm})$ substrates partially masked with different temperature sensitive materials. The masking materials were polydimethylsiloxane (PDMS), polymethylmethacrylate (PMMA), polystyrene (PS), and parafilm. Other non-conventional materials, such as Kapton tape, Scotch tape and office paper, were also tested as masking materials for ASD. Both sections of the substrate, masked and unmasked, were biased with $+40 \mathrm{~V}$ and the deposition temperature was $40{ }^{\circ} \mathrm{C}$ for $60 \mathrm{~s}$. The results show that the films deposited on the unmasked areas of the substrates consist mainly of iron, whereas no film materials could be found on the masked area of the substrate after mask removal. The masking materials showed no deformation nor damages after deposition. This indicates that the new CVD method is truly a low temperature process. In addition, deposition with masking materials with no adhesive contact materials show that the film deposition extends 50-100 $\mu \mathrm{m}$ to the mask area indicating that the CVD process a not line-of-sight method. More details in Paper III of this thesis. 


\title{
4. Characterization Techniques
}

\subsection{Scanning Electron Microscopy}

Scanning electron microscopy (SEM) is a powerful imaging technique that is widely used for material characterization, especially when the size of materials in many applications decreases over time. Resolution of up to $0.4 \mathrm{~nm}$ together with 3,000,000x magnification are what make SEM a technique for studying surface morphology and structure of different materials. SEM consists mainly of a vacuum chamber, an electron source (electron gun), electromagnetic condenser lens, scanning coils, electromagnetic lenses and objective, sample holder and detectors [116], Fig. 4.1.

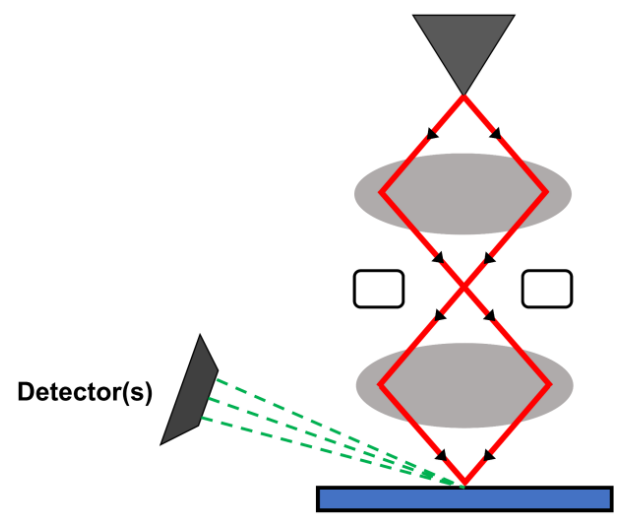

\author{
Electron gun \\ Condenser lens \\ Scan coils \\ Objective lens \\ Sample
}

FIGURE 4.1. A schematic of a SEM configuration.

The basic working principle of SEM depends on the interaction of high energy electron beam (1-30 keV) with sample material atoms. The interaction results in different processes, such as electron backscattering, secondary electron emission, electron absorption, electron transmission, cathodoluminescence, radiation emission (X-ray), etc., Fig. 4.2. Each of these processes provides different information about the sample material. For instance, backscattering electrons (BSE) are used to study the compositional differences in the sample, i.e., compositional contrast. The secondary electron emission process is used to for surface imaging and, usually, is the most utilized mode in SEM. When the electron beam interacts with the atom of the sample, an inelastic scattering interaction occurs. Such inelastic interaction leads 
to the excitation of low energy electrons from the valence or conduction band of the atom. Due to the low energy of these electrons, the electrons emitted from the surface have much hight probability to escape into the vacuum, therefore used for surface imaging. A detector then collect these electrons, by attracting them using a positive biased grid, accelerate and convert them into photons which can then be displayed using a photomultiplier system. Images are produced by scanning the sample surface in parallel lines [116].

The X-ray emission is used for composition identification and distribution, such process is called energy dispersive X-ray spectroscopy (EDS or EDX). When a core level electron is ejected from the inner shell of an atom, a hole is created. The hole is then filled by an electron from an outer and higher energy shell of the atom. The energy difference between these shells is emitted in form of X-ray photons. The energy released is unique to each element of the periodic table, thus, the emitted X-ray is characteristic for each element $[116,117]$.

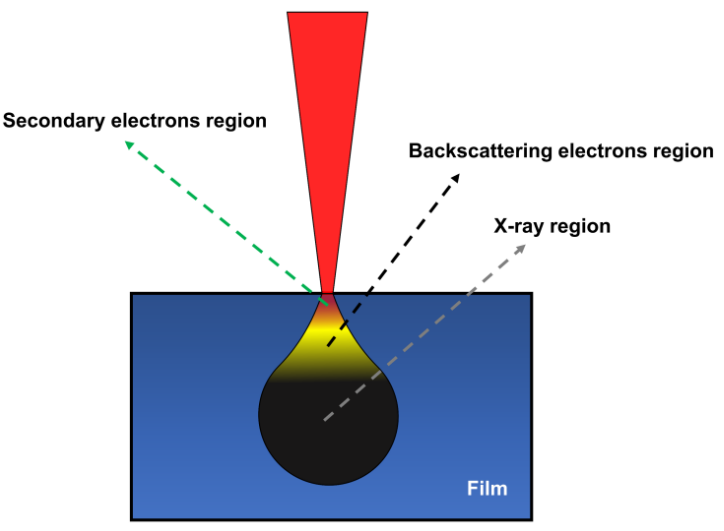

FIGURE 4.2. A schematic of the excitation volume in SEM and different processes that occur as result of electron-sample interaction.

SEM requires UHV to acquire high-resolution images, and to increase the mean free path of the emitted electrons and X-rays to reach the detector, and also for the electron beam to reach the sample. SEM also requires electrically conductive samples. Although, electrically insulating and biological sample can also be analysed by coating them with a thin electrically conductive film. Charging is another issue when using SEM, especially when using poorly conducting materials, which causes poor resolution images. Such an issue can be avoided by electrically grounding the surface of the sample [116]. 
In this thesis, I used SEM in imaging mode (secondary electron mode) and EDS in elemental mapping mode to characterize the surface morphology and to analyze the surface composition, respectively. The images were acquired using a LEO 1550 Gemini SEM instrument with a field emission gun (FEG) as an electron source with an acceleration voltage of $3 \mathrm{kV}$. The surface composition and elemental mapping was acquired, with help from an expert in the area, using the same SEM system with an acceleration voltage of 15-20 kV. More information can be found in Paper I - III of this thesis.

\subsection{Transmission Electron Microscopy}

Transmission electron microscopy (TEM) is a very powerful tool that is widely used for material characterization. The atomic resolution and the high magnification are what make TEM a very powerful technique for studying surface morphology, material composition, chemical analysis, defects, crystal structures, structure properties (e.g., dislocations and grain boundaries), etc. Like SEM, TEM consists mainly of a vacuum chamber, an electron source (electron gun), electromagnetic lenses and objectives, sample holder and detectors. The basic working principle of TEM is similar to light microscopy, however electrons are used instead of light. In contrast to SEM, the high-energy electron beam is transmitted through the sample, resulting in electron scattering and/or diffraction that can be used for conventional imaging and/or diffraction imaging. An operation mode in TEM is scanning transmission electron microscopy (STEM), where the electron beam is focused on a small area and is rastered (scanned) across the sample surface where varies signals are collected to form an atomic image. In addition, and similar to SEM, X-ray spectroscopy analysis (EDS or EDX) can be done in TEM for elemental and chemical analysis. Since the electron beam have to pass through the sample, the sample have to be very thin, usually less than $100 \mathrm{~nm}$ [118]. Thus, comprehensive sample preparations are required.

In this work, cross section scanning transmission electron microscopy (STEM) was done by an expert in the area. I discussed the analysis results that is used to determine the existence, thickness and chemical structure of the deposited iron films for area-selective purposes. The analysis was preformed using a FEI Tecnai G2 TF 20 UT instrument operated at $200 \mathrm{kV}$. The composition of the deposited films layers was determined by EDS analysis and elemental mapping in the same TEM system. More information can be found in Paper II and III of this thesis. 


\subsection{X-Ray Photoelectron Spectroscopy}

X-ray photoelectron spectroscopy (XPS) is a quantitative surface analysis technique where information, such as elemental composition, chemical boding structure and chemical state, stoichiometry, and distribution of elements, can be obtained. The basic principle of operation is based on the photoelectric effect, which is the interaction of light (photons) with matter. When X-ray (photons) with known energy, $h v$, interact with a core electron of an atom in the matter, the core electron leaves the atom, and the atom becomes ionized. This effect take place only when the X-ray have higher energy than the ionization energy of the atom. The excess energy converts to electron kinetic energy, $E_{k i n}$. This kinetic energy of the so-called photoelectron is then measured by the instrument and the binding energy, $E_{b i n}$, of the core electron can be determined by using the photoelectric effect equation:

$$
E_{b i n}=h v-E_{k i n}-\phi
$$

where $\phi$ is the work function of the spectrometer (instrument constant) [119-122].

Each element has a unique electron configuration in the atom, which means that the kinetic energies of the emitted photoelectrons are characteristic and well defined for each element. Thus, each element produces a unique set of peaks in a spectrum, providing composition information about the sample. All elements can be detected (except $\mathrm{H}$ and $\mathrm{He}$ ), provided that their atomic percentage (at. \%) in the sample are greater than the detection limit, which is often in the $0.1-1$ at. $\%$ range (100 ppm may also be achieved in certain conditions). Typically in XPS, a spectrum is obtained by plotting the number the electron detected (intensity) versus the corresponding binding energies. The number of the detected electrons at a specific energy is directly proportional to the amount of element in the sample material. The binding energy of an element depends on the formal oxidation state and the chemical environment of the element in the sample material. When an element is bonded to a more electronegative element, the higher electronegative element tends to attract the surrounding electrons of the less negative element, which leads to that the density of electrons around the less electronegative element decreases and the binding energies increases. Thus, shifting of the peaks position towards higher energies in the XPS spectrum. Conversely, when an element is bonded to a less electronegative element, the surrounding electrons density increases and the binding energy decreases, thus, shifting of the peaks position towards lower energies in the XPS spectrum. Analogically, when the oxidation state of an element increases, the binding energy increases and vice versa [119-122]. 
To investigate the chemical bonding structure and chemical state of the element present in the sample material, high energy resolution XPS (HR-XPS) is used. (Low resolution XPS is usually used for qualitative and quantitative analysis of the elements). To be able to detect the photoelectrons emitted from sample, the photoelectrons must travel through the sample, into vacuum in the instrument and reach the detector. While traveling through the sample, the photoelectrons undergo different processes before leaving the sample, such as inelastic collisions, recombination, excitation, etc., which can reduce the number of escaping photoelectrons. The effect of such process increases exponentially with depth. This means that the photoelectrons at the surface have much higher probability to escape into the vacuum. This is why XPS considered to be a surface analytical technique [119-122].

There are however a few limitations using XPS. XPS requires ultra-high vacuum (UHV) to increase the mean free path of the escaped photoelectrons to reach the detector and for the X-ray photons to reach the sample. Due to the extremely small photoelectron cross-section and the lack of core electrons, hydrogen and helium cannot be detected in XPS. The samples should solid and electrically conductive. Although, electrically insulating materials can also be analysed in XPS, however charging effect must be considered. Charging leads to shifts in the spectrum and can prevent the formation of photoelectrons. To overcome the charging issue, an electron flood gun can be used to compensate for the charging effect. Another issue that is normally encountered is surface oxidation and contamination of the sample material which usually lead to incorrect and inaccurate results using XPS. Therefore, argon sputtering is usually used to the remove surface oxides and other contamination on the film surface prior to XPS measurements. Argon sputtering can also be used for subsurface analysis of the sample, i.e., depth profiling. This is done by alternating the sputtering process and analysis [119-122].

Regarding the characterization of $\mathrm{Fe}, \mathrm{Ni}$ and Co films, XPS is an excellent technique that can be used to detect Fe, Ni and Co, C and O. HR-XPS can also be used in depth profiling mode (with Ar sputtering) to determine the chemical bonding structure and the chemical state of $\mathrm{Fe}$, $\mathrm{Ni}$ and $\mathrm{Co}$ in the sample material. TAB. 4.1 shows the reported peak positions for $\mathrm{Fe}, \mathrm{Co}, \mathrm{Ni}$, $\mathrm{C}$ and $\mathrm{O}, \mathrm{N}, \mathrm{Ti}$, and $\mathrm{Ag}$. 
TABLE 4.1. Reported XPS peak positions for peaks relevant for the analysis of $\mathrm{Fe}, \mathrm{Co}$, and Ni films deposited in this thesis.

\begin{tabular}{|c|c|c|c|}
\hline Element & BE (eV) & Attribution & Reference \\
\hline \multirow{4}{*}{$\mathrm{Fe}$} & $707-707.1$ & $\overline{F e} 2 p_{3 / 2}$ & {$[123-125]$} \\
\hline & $720.1-720.2$ & Fe $2 p_{1 / 2}$ & [123-125] \\
\hline & $710.9-711$ & $\mathrm{Fe}_{2} \mathrm{O}_{3} 2 \mathrm{p}_{3 / 2}$ & {$[123,125]$} \\
\hline & $724.5-724.6$ & $\mathrm{Fe}_{2} \mathrm{O}_{3} 2 \mathrm{p}_{1 / 2}$ & {$[123,125]$} \\
\hline \multirow{4}{*}{ Co } & $778-778.5$ & Co $2 \mathrm{p}_{3 / 2}$ & [125-127] \\
\hline & $793-793.6$ & Co $2 \mathrm{p}_{1 / 2}$ & {$[125,126]$} \\
\hline & $780.0-781.1$ & $\mathrm{CoO} 2 \mathrm{p}_{3 / 2}$ & {$[125,126,128]$} \\
\hline & $795.6-796.2$ & $\mathrm{CoO} 2 \mathrm{p}_{1 / 2}$ & {$[125,126]$} \\
\hline \multirow{5}{*}{$\mathrm{Ni}$} & 852.6 & $\mathrm{Ni} 2 \mathrm{p}_{3 / 2}$ & {$[125,127-129]$} \\
\hline & $870-870.1$ & $\mathrm{Ni} 2 \mathrm{p}_{1 / 2}$ & {$[125,129]$} \\
\hline & $853.7-854.1$ & $\mathrm{NiO} 2 \mathrm{p}_{3 / 2}$ & {$[125,128,130]$} \\
\hline & $871.3-873.5$ & $\mathrm{NiO} 2 \mathrm{p}_{1 / 2}$ & {$[125,130]$} \\
\hline & $854.9-855.8$ & $\mathrm{Ni}(\mathrm{OH})_{2}$ & {$[128,131]$} \\
\hline \multirow{3}{*}{$\mathrm{O}$} & $529-530.2$ & O-Metal bond & {$[125,128]$} \\
\hline & $530.9-532$ & $\mathrm{O}-\mathrm{C}$ bond & {$[125,132]$} \\
\hline & $533-534$ & $\mathrm{O}=\mathrm{C}$ bond & {$[125,132]$} \\
\hline \multirow{3}{*}{$\mathrm{C}$} & $284.2-285.2$ & $\mathrm{C}-\mathrm{C}$ bond & {$[125,132]$} \\
\hline & $286.1-286.8$ & $\mathrm{C}-\mathrm{O}$ bond & {$[132,133,134]$} \\
\hline & $287.6-288.9$ & $\mathrm{C}=\mathrm{O}$ bond & {$[132,133,134]$} \\
\hline $\mathrm{N}$ & 398 & $\mathrm{~N} 1 \mathrm{~s}$ & [125] \\
\hline \multirow[t]{2}{*}{$\mathrm{Ti}$} & 458.6 & $\mathrm{TiO}_{2} 2 \mathrm{p}_{3 / 2}$ & [125] \\
\hline & 464.2 & $\mathrm{TiO}_{2} 2 \mathrm{p}_{1 / 2}$ & [125] \\
\hline $\mathrm{Ag}$ & 719 & $\operatorname{Ag~3s}$ & {$[125]$} \\
\hline
\end{tabular}

In this thesis, the XPS was performed by a specialist in the area, and I did the analysis/interpretation of the results data. HR-XPS in depth profiling mode with Ar sputtering was used to analyse elemental composition and chemical bonding in the deposited films using a Kratos AXIS Ultra DLD instrument with a monochromatic $\mathrm{Al} K_{\alpha} \mathrm{X}$-ray source in an analysis 
chamber with a base pressure of $10^{-8} \mathrm{~Pa}$. A charge neutralizer filament was used to compensate for the charge build-up effect. The conditions used for survey scans were as follows: energy range $=0-1200 \mathrm{eV}$; pass energy $=160 \mathrm{eV}$; step size $=0.1 \mathrm{eV}$; and $\mathrm{x}$-ray spot size $=2 \mathrm{~mm}$ in diameter. A binding energy range of $20-40 \mathrm{eV}$ (depending on the examined peak) was used for high-resolution spectra with a pass energy of $20 \mathrm{eV}$. Argon $(0.5 \mathrm{keV})$ was used as the sputtering source. XPS spectra was analysed using the CASAXPS software where the $C_{1 \text { s }}$ peak with a value of $285 \mathrm{eV}$ was used for calibration in all spectra. Gaussian-Laurentius (GL) functions and Shirley background were used to fit all the experimental data.

\subsection{X-Ray Reflectometry}

$\mathrm{X}$-ray reflectometry (XRR) is an X-ray technique that is used to characterize thin film structures where information, such as thicknesses, roughness, and densities, can be obtained.

A typical XRR measurement is done by recording a $2 \theta / \omega$ scan, when $\omega$ is the parallel incident $\mathrm{X}$-ray and $2 \theta$ is the reflected X-ray (usually $0.1^{\circ}<2 \theta<10^{\circ}$ ), Fig. 4.3. The basic principle of XRR is based on the reflection of X-ray at a surface or an interface. When a beam of X-ray interacts with a sample surface at low angels, the X-ray will either gets totally reflected from top surface of the sample or penetrates the sample, depending on the so-called critical angle of the sample material. Below the critical angle, total external reflection occurs. Above the critical angel, penetration occurs, and increases rapidly. When the X-ray penetrates the sample, every interface in the sample with different refractive index reflects a part of the X-ray beam. The interference of the reflected beams creates a certain oscillating pattern called Kiessig fringes $[135,136]$.

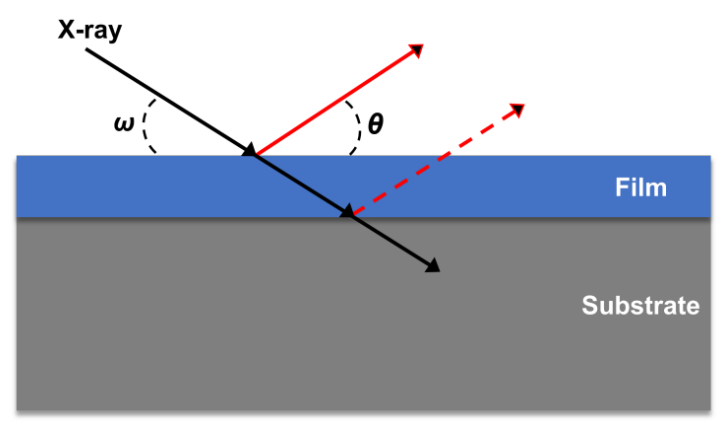

FIGURE 4.3. A schematic representing the XRR basic configuration. 
Modeling (fitting) and interpreting the Kiessig fringes, allow information such as thickness and densities of each layer to be obtained, as well as surface and interface(s) roughness. The film thickness (and the thickness of every film in a multilayer sample) can be obtained by determining the spacing between two fringes ( $\approx$ wavelength/film thickness). The critical angle is proportional to the density (electron density) of the film allowing density determination. Fringe amplitude may also change with the density. Roughness and interface roughness can be quantified by studying the fringes amplitude, the shape of the curve and the decay of the X-ray beam $[135,136]$.

Using XRR require knowledge regarding the modeling of the X-ray reflectogram and can be difficult for complex films. Films with thicknesses less than a few $\mathrm{nm}$ or more than $100 \mathrm{~nm}$ cannot be analyzed with XRR. Also, XRR is not applicable for films with high surface roughness.

In this thesis, I did the XRR measurements with help from experts. The data fitting were done together with specialists in data analyses. XRR was used to measure film thicknesses and densities using PANalytical EMPYREAN MRD XRD with a Cu-anode X-ray tube and a 5-axis (x-y-z-v-u) sample stage. XRR data fitting was carried out using the PANALYTICAL X'PERT reflectivity software.

\subsection{Quartz Crystal Microbalance}

Quartz crystal microbalance (QCM) is a sensitive analysis technique that measures mass changes, down to nanogram, per unit area. QCM is widely used in many fields, such as chemistry, biology, materials science, etc. In thin film processing (e.g., CVD and PVD), QCM is extensively used as an in-situ analysis technique to monitor surface processes during film deposition. For instance, in CVD, QCM can be used to observe surface-precursors interactions (e.g., molecule adsorption and desorption), film growth, thickness, deposition rate, etc., that deepens the understanding of processes occur during film deposition [137].

QCM can operates in vacuum, in gas, and in liquid environments. In CVD, QCM is usually used in vacuum. The QCM instrument consists usually of a QCM plate (quartz crystal that is usually coated with gold), a holder (that houses the QCM plate), data cables (transmitting the data from the QCM to the monitoring devices), cooling system, and monitoring devices (e.g., a QCM monitoring unit). The working principle of QCM is based on the piezoelectric effect, i.e., 
the ability of certain materials to generate electricity when a mechanical stress is applied, and vice versa. Quartz crystals is a class of piezoelectric materials that when an external electric field is applied to the QCM, the crystals generate mechanical stress that causes the crystals to oscillate/vibrate at a constant and measurable rate. As material is deposited on the QCM crystal, the crystal oscillation frequency decreases due to mass accumulation on the crystal, and the mass change is immediately registered by the monitoring unit, Fig. 4.4. The relation between the frequency change and the mass change is a linear relationship described by Sauerbrey's equation:

$$
\Delta m=-C \cdot \frac{\Delta f}{n}
$$

Where $\Delta m$ is the mass change, $\Delta f$ is the frequency change, $C$ is the mass sensitivity constant which is related to the properties of the quartz, and $n$ is the overtone order (the number of harmonic) [137].

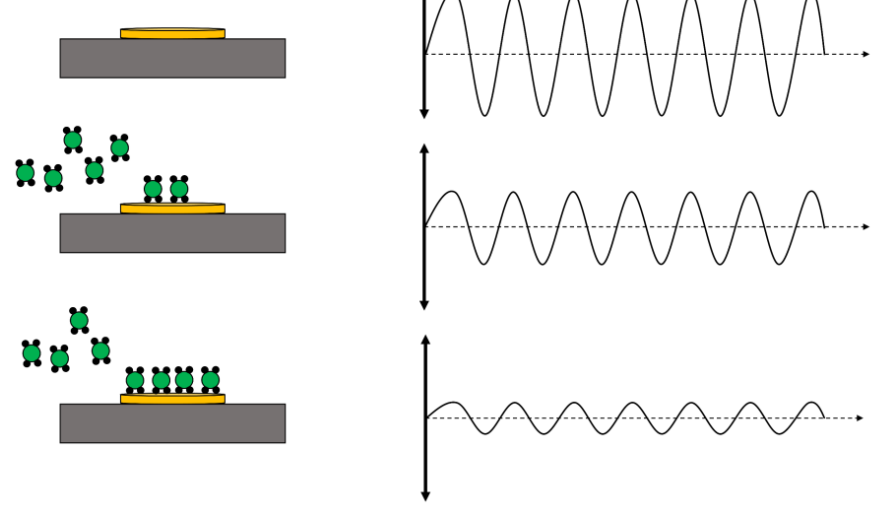

FIGURE 4.4. A schematic of the operation principle of QCM.

In this thesis, a new, positively biased, QCM method has been developed (Paper IV of this thesis) to be able to obtain a better understanding of the physical and chemical processes in our newly developed CVD method (Paper I), such as film growth, thicknesses, deposition rate, the effect of plasma parameters and bias voltage on film deposition. Here, the silver substrate was replaced with a QCM sensor where the QCM gold coated crystal was used as a low electrically resistive substate. Iron, from ferrocene, was used to investigate the new QCM approach with a bias voltage of $-40 \mathrm{~V}$ to $+40 \mathrm{~V}$ and with a plasma power of 5-15 $\mathrm{W}$. The deposition pressure 
was 45-50 Pa and the deposition time was 60 s. Detailed information can be found in Paper IV.

The QCM instrument used was a conventional QCM sensor, with a $6 \mathrm{MHz}$ gold coated crystal (Allectra), connected to an external oscillator (MCVAC) and a TFM260 (Beamtec) thin film monitoring unit. SQM160 software (Inficon) was used to collected and analyzed the measured data during depositions. The electrical connection of the QCM was modified to allow a positive bias voltage to be applied to the QCM crystal without interfering with the QCM signals, Fig. 4.5.

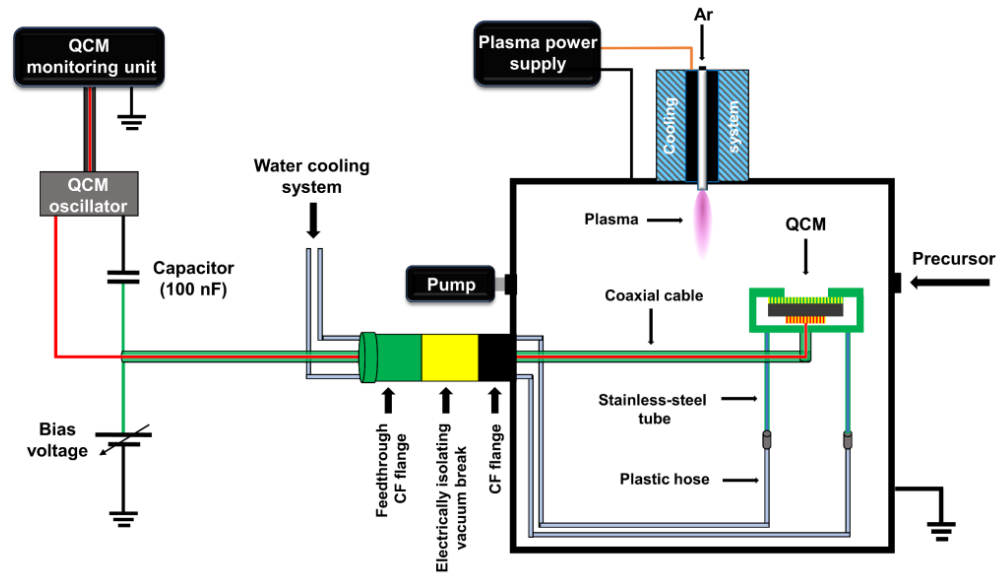

FIGURE 4.5. A schematic of the modified QCM used in the experimental setup. The use of different colors in electrical scheme of the QCM system is reflecting the different potentials (red - the QCM high frequency signal, green - the bias voltage, black - ground).

The ground connection of the QCM oscillator was connected to the top electrode of the crystal through a capacitor $(100 \mathrm{nF})$ which allows for the QCM frequency signal to pass through and to prevent the DC biasing voltage applied to the crystal's top electrode from entering the QCM oscillator. In this configuration, the top crystal electrode could be biased without any influence on the QCM function. The QCM sensor was connected by a coaxial cable through a BNC electrical feedthrough $\mathrm{CF}$ flange, which was electrically isolated from the grounded stainless-steel chamber by an insulating polytetrafluoroethylene (PTFE) vacuum break. The QCM sensor was also connected to a water-cooling system by PTFE hoses to also isolate the QCM sensor electrically from the grounded stainless-steel chamber. More information can be found in Paper IV of this thesis. 


\section{Contribution to the Field}

The focus of this thesis is the development of a new low temperature chemical vapor deposition (CVD) method for metal films, where plasma electrons are used as reducing agents, and to explore how the new method can be used for area-selective deposition (ASD) of metallic films.

The work in Paper I was dedicated to demonstrating that plasma electrons can be used as reducing agents for metal films deposition by depositing the challenging, first-row transition metals iron, cobalt, and nickel on substrates with different resistivities, using the newly developed method. All experiments were done in a homemade CVD system (Fig. 5.1) consisting mainly of a vacuum chamber, a titanium hollow cathode plasma source, a biased substrate holder, and a precursor chamber/bubbler. The precursor used was bis(cyclopentadienyl)M(II) $\left(\mathrm{MCp}_{2}\right)$, where $\mathrm{M}=\mathrm{Fe}, \mathrm{Co}$, or $\mathrm{Ni}$, to deposit iron, cobalt, and nickel films, respectively. The depositions were done at a pressure of 45-60 $\mathrm{Pa}$ for $60 \mathrm{~s}$ with temperatures in the range of $35-50{ }^{\circ} \mathrm{C}$. The plasma was generated with $70 \mathrm{sccm}$ argon gas using 50-150 W of DC power. The substrate holder was place upstream from the plasma and was electrically biased in the range of $-40 \mathrm{~V}$ to $+80 \mathrm{~V}$ using a DC bias voltage supply. More descriptions on the CVD system and the deposition method can be found in Paper I.

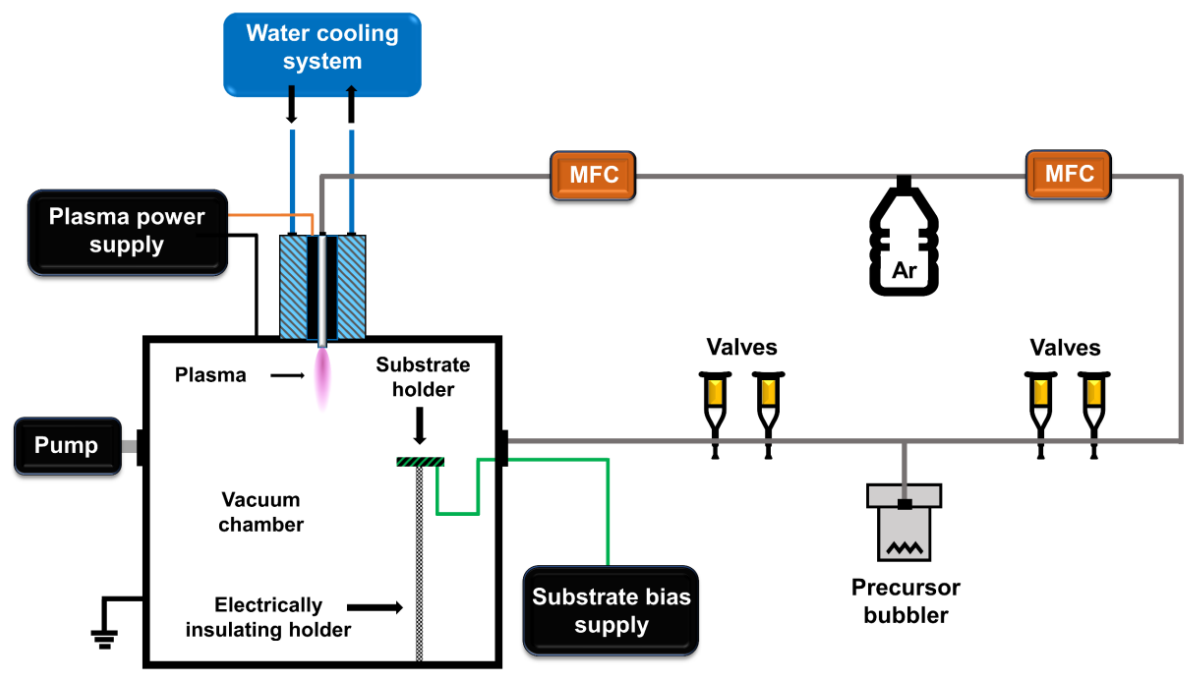

FIGURE 5.1. A Schematic of the newly developed CVD system "GONZO". 
The feature of this method is that the plasma electrons are used to reduce the metals with positive valence to metals with zero valence by an electron-precursor surface redox chemistry, which differs from conventional CVD, where molecular reducing agents are used, and PECVD (described in Section 2.2). For the surface reaction to occurs, the plasma electrons are attracted to the substrate surface by applying a positive bias, with a voltage of $0-40 \mathrm{~V}$. Figure 5.2 shows the compositional analysis by X-ray photoelectron spectroscopy (XPS) of iron films deposited without plasma at $+40 \mathrm{~V}$ (and $-40 \mathrm{~V}$ ) substrate bias voltage, where precursor condensation is the only possible process that may occurs.
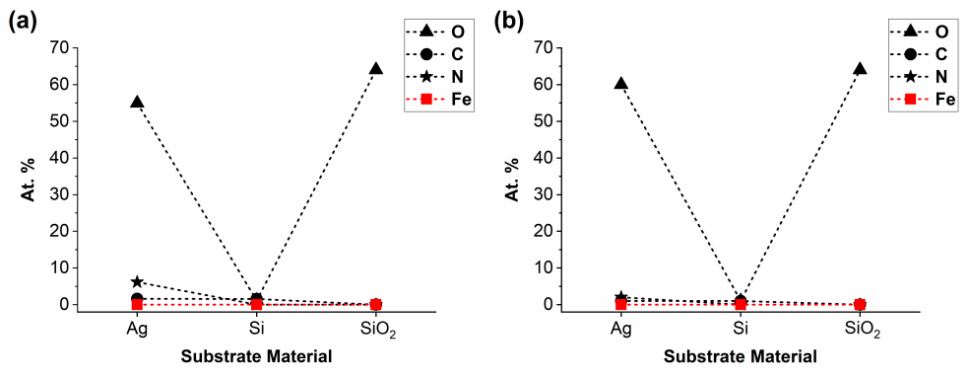

FIGURE 5.2. Film composition from XPS for iron films deposited on different substrate materials with no plasma at (a) $+40 \mathrm{~V}$ and (b) $-40 \mathrm{~V}$ substate bias voltage.

The results show that films do not grow when electrons are absent and the present elements/impurities, i.e., O, N and C, belong to the substrate surface material. Similar results can be seen when the plasma is applied with a substrate bias of $-40 \mathrm{~V}$ where the plasma electrons are repelled, whereas a positive substrate bias of $+40 \mathrm{~V}$, attracting the electrons to the substrate, resulted in metallic film growth of iron, cobalt, and nickel, Fig. 5.3.
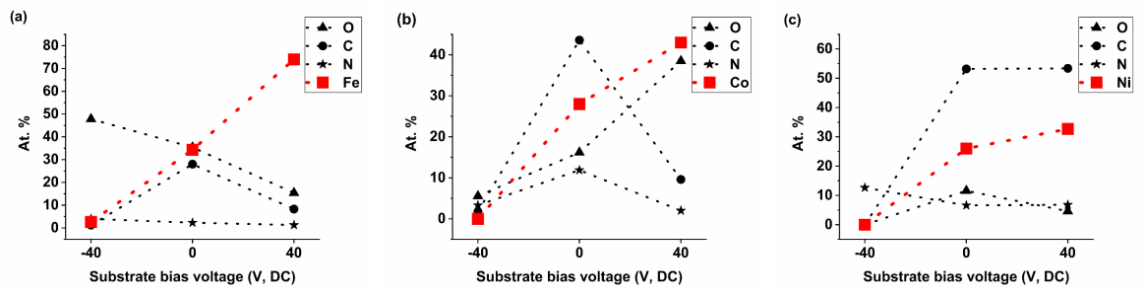

FIGURE 5.3. The substrate bias effect on the film composition from XPS for films of (a) Fe, (b) Co and (c) Ni. All films were deposited on silver substrates with a plasma power of $70 \mathrm{~W}$ for $\mathrm{Fe}$ and $\mathrm{Co}$ deposition and $50 \mathrm{~W}$ for Ni deposition. Note the different scaling of the y-axes. 
These results indicate that it is the plasma electrons that cause metal film deposition, presumably by surface chemical reactions. Furthermore, to allow the electrons to pass through the substrate and to the substrate holder, for a closed electric circuit, a substrate with low electrical resistivity is required. This requirement is investigated by deposition iron, cobalt, nickel on low resistive $40 \mathrm{~nm}$ silver on top of silicon, semiconductive silicon, and high resistive $300 \mathrm{~nm}$ thermally grown silicon dioxide on silicon substrates. The results show that for films deposited on silver substrate, the amount of iron, cobalt, and nickel was up to 74, 43, and 33 at. $\%$, respectively, whereas films deposited on the semiconductive silicon substrates resulted in less than half the amount of that (Fig. 5.4). Films deposited on silicon dioxide substrates resulted in no films, which is further investigated in Paper II. This indicates that the deposition method is highly dependent on the electrical resistivity of the substrate. Moreover, electron attraction to the substrate surface causes a small heating of the substrate to temperatures of $35-50{ }^{\circ} \mathrm{C}$, depending on the applied substrate bias and the deposition time. This is regarded as the deposition temperature since no additional heating is applied.

(a)

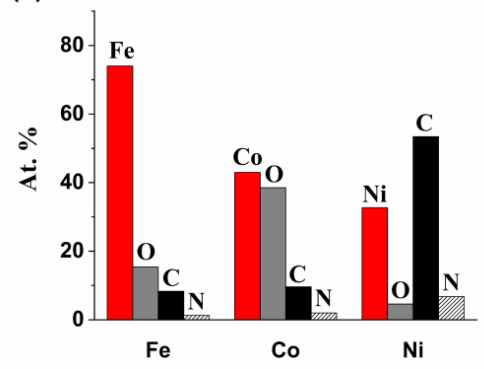

(b)

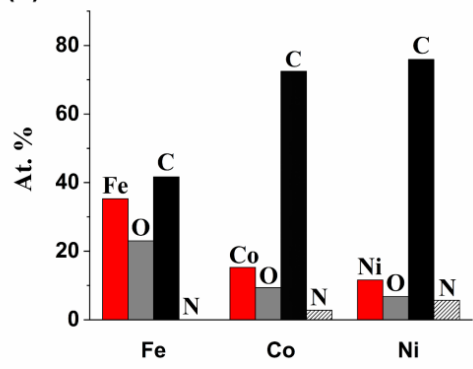

FIGURE 5.4. Elemental composition from XPS of the films deposited on (a) silver and (b) silicon, after sputter cleaning. The substrate bias was $+40 \mathrm{~V}$.

In Paper II, the dependency of newly developed CVD method on the substrate electrical resistivity is further investigated, which led to the study of ASD of metal films utilizing the substrate electrical resistivity properties. For this purpose, iron films from ferrocene, bis(cyclopentadienyl)Fe(II) $\left(\mathrm{FeCp}_{2}\right)$, were deposited on high resistive $\mathrm{SiO}_{2}$ substrate that was partially coated with $40 \mathrm{~nm}$ low resistive silver, where both parts were biased with $+40 \mathrm{~V}$. The deposition time was $60 \mathrm{~s}$ with a deposition temperature of $40{ }^{\circ} \mathrm{C}$. The results show that several hundred nm of iron films, consist of 40 at. \% Fe, 19.5 at. \% C, 35 at. \% O, 2.6 at. \% N and 2.9 at. $\% \mathrm{Ti}$, can selectively grow on the low resistive area of the substrate, i.e., the silver, whereas 
no, or very minor, films growth on the high resistive $\mathrm{SiO}_{2}$ (Fig. 5.5). The low resistivity of silver creates an easy pathway for the electrons to cross that leads to surface chemical reactions which is essential in the new CVD process. Thus, this CVD process is inherently ASD and does not depend on any thermodynamic or kinetic factors, comparing to other ASD processes [138].

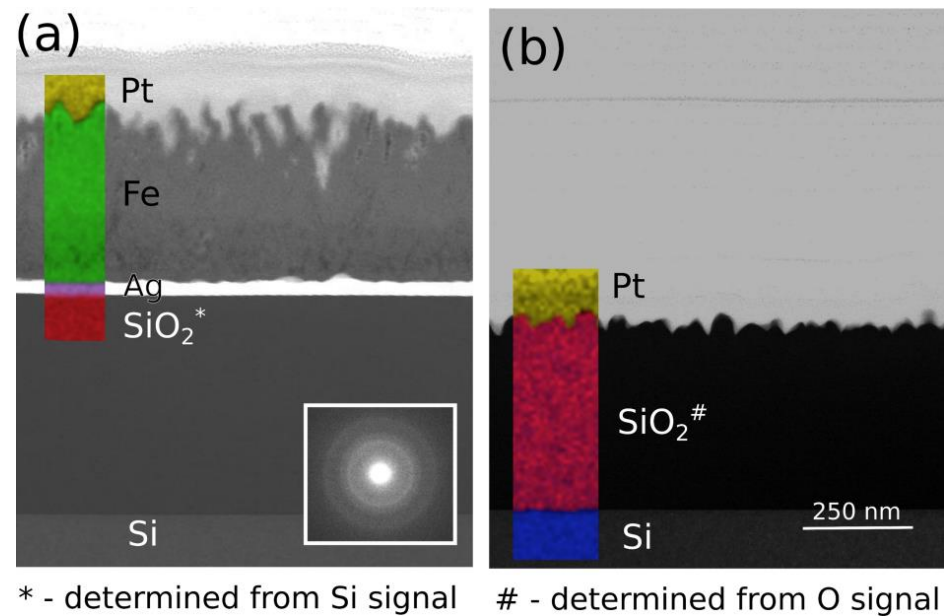

FIGURE 5.5. Cross sectional scanning transmission electron micrographs, with EDS mapping, of the substrate regions where (a) with Ag coating and (b) without Ag coating.

In Paper III, the low deposition temperature of the new CVD method is explored for robust, cheap, and straightforward ASD with a different approach, i.e., by using temperature sensitive masking materials. In these experiments, iron films from ferrocene, bis(cyclopentadienyl)Fe(II) $\left(\mathrm{FeCp}_{2}\right)$, were deposited on $40 \mathrm{~nm}$ silver/silicon substrates that were partially masked with simple and widely available polymer-based materials. The masking materials used were polydimethylsiloxane (PDMS), polymethylmethacrylate (PMMA), polystyrene (PS), parafilm, Kapton tape, Scotch tape, and office paper. All substrates were biased with $+40 \mathrm{~V}$ for $60 \mathrm{~s}$ and the deposition temperature was $40{ }^{\circ} \mathrm{C}$. The results show that films deposited on the unmasked $\mathrm{Ag}$ area consist of $35-45$ at. $\% \mathrm{Fe}, 18-30$ at. $\% \mathrm{C}, 30-35$ at. $\% \mathrm{O}, 2-3$ at. $\% \mathrm{~N}$ and $3-7$ at. \% Ti, whereas no film material is found on the masked areas after mask removal, Fig. 5.6 and 5.7. Here, two conclusions can be drawn regarding the new CVD method: it is indeed a low temperature CVD process, since none of the masking materials were affected by the deposition process; and it is not a line-of-sight technique, where films could be seen in the very adjacent masked areas (extends in a variation of 50-100 $\mu \mathrm{m}$ to the masked area). 

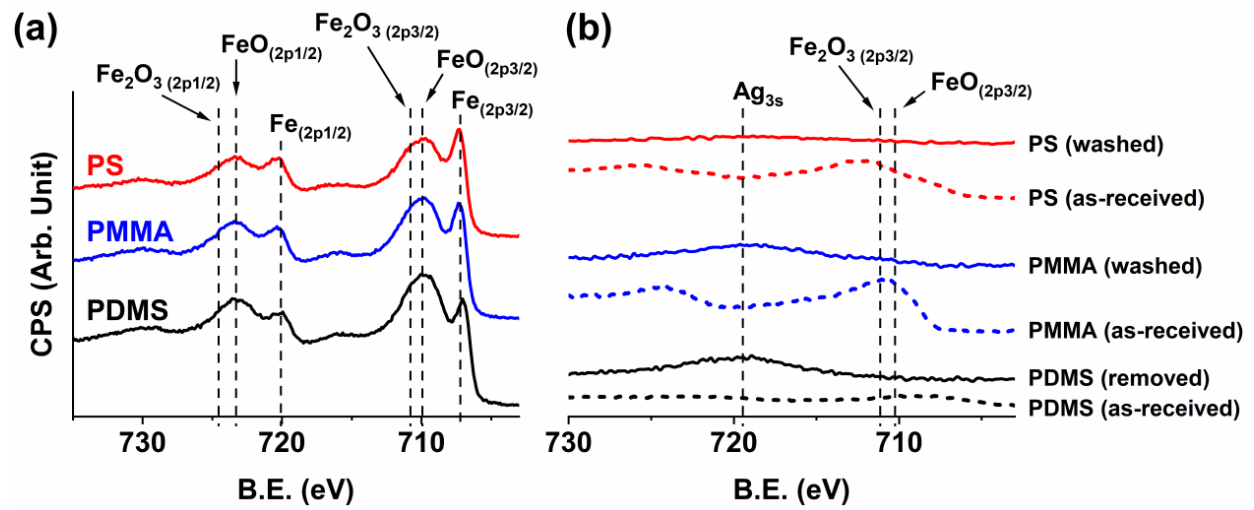

FIGURE 5.6. High resolution XPS showing the iron region of films deposited on the substrate areas with (a) unmasked $\mathrm{Ag}$ and (b) with $\mathrm{Ag}$ masked by polymers, before and after polymer removal. (The sample surfaces in (a) and (b) were analyzed as-received and were not sputter cleaned).
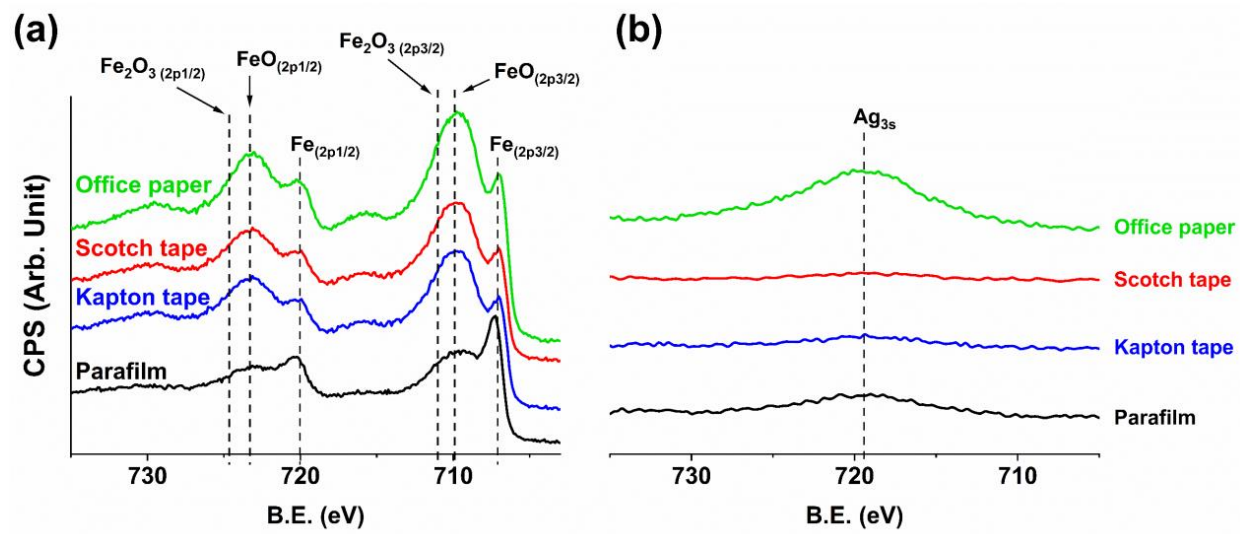

FIGURE 5.7. High resolution XPS showing the iron region of films deposited on the substrate areas with (a) unmasked Ag and (b) with masked Ag, after mask removal. The samples in (a) were exposed to air for longer period of time before XPS analysis, therefore the surfaces of these samples were sputter cleaned with Ar for $600 \mathrm{~s}$ before XPS analysis. The samples in (b) were analyzed as-received, before and after mask removal. 
From the work accomplished in Paper I, II and III, the highlights of the new CVD method can be summarized as following:

- It is a low temperature method, which is highly useful in many applications and for temperature sensitive material depositions. The advantage of the low temperature properties is utilized in Paper III, where temperature sensitive masking materials are used for area-selective deposition (ASD).

- Very high deposition rate can be achieved on substrates with low resistivity (Paper II).

- It uses only the plasma electrons, hence reducing the process complexity compare to PECVD.

- Because it uses electrons as reducing agents for surface chemical redox reactions, we believe that by modifying the deposition parameters, it can be utilized to deposit many other metals (e.g., Ru, Ir, and Ag), including the challenging first-row transition metals (e.g., $\mathrm{Cr}$ and $\mathrm{Ti}$ ) that require either high temperatures or powerful reducing agents.

- It is not a line-of-sight process, which has been shown in Paper III.

- Also, since electrons are used as reducing agents, single-source precursors can be used, which reduces the requirement for molecular co-reactant (co-reagent or reducing agents).

- It is dependent on the electrical resistivity of the substrate surface, which allows to control the film grow. This has been utilized for inherent ASD of metal-on-metal by substrate resistivity in Paper II.

- Because the process reactions are surface reactions, in additional to the ability of using single-source precursors, we believe that the amount of waste/hazardous by-product(s) can be reduced compare to conventional CVD.

- The combination of the low deposition temperature, the ability of using single-source precursors, and the relatively low energy used to operate the whole process, makes the method more environmentally friendly, i.e., it can be regarded as Green CVD.

The newly developed CVD, and ASD, is in its embryonic stage and further research and investigations are needed. We have only obtained a phenomenological understanding of the new CVD process, the chemical and physical processes controlling the deposition process are still unclear. Also, using the same set of metal precursors, i.e., $\mathrm{M}(\mathrm{Cp})_{2}$, in our CVD method resulted in a puzzling trend in metal and impurities content, (Fig. 5.4) that does not follow the 
reported binding strength of cyclopentadienyl ligands to the metal center, where the binding enthalpy increases as $\mathrm{NiCp}_{2}<\mathrm{FeCp}_{2}<\mathrm{CoCp}_{2}$ [139-145].

To understand the deposition processes in our new CVD method, a modified in-situ quart crystal microbalance analysis (QCM) instrument was developed. In Paper IV, a conventional QCM instrument was used in such way that the gold coated crystal of the QCM sensor was used as a substrate, and the electrical connection of the QCM was modified to allow bias voltage to be applied to the QCM sensor without interfering with the QCM measurements. Such configuration allowed us to imitate the deposition setup used in Paper I (where a $40 \mathrm{~nm} \mathrm{Ag/Si}$ was used as a substrate with $+40 \mathrm{~V}$ of bias voltage), and to observe the film growth during film deposition. Here, iron films, from ferrocene, was deposited on the gold coated QCM crystal using a plasma power of 5-15 $\mathrm{W}$ and a bias voltage in range of $-40 \mathrm{~V}$ to $+40 \mathrm{~V}$. The deposition time was $60 \mathrm{~s}$ with a deposition pressure of $45 \mathrm{~Pa}$. The results show that iron film can be deposited on gold coated QCM crystal and that the film deposition process is highly dependent on the polarity of the applied bias voltage on the QCM sensor, Fig. 5.8. These results are in agreement with the results presented in Paper I (where $40 \mathrm{~nm} \mathrm{Ag} / \mathrm{Si}$ was used as a substrate).

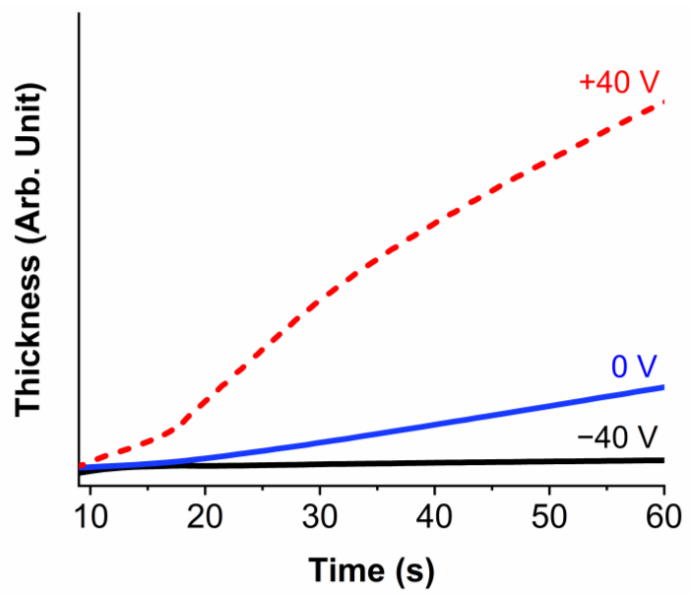

FIGURE 5.8. QCM measurements showing the effect of the applied bias voltage on iron film growth, where the QCM crystal is used as a substrate. The plasma power was $10 \mathrm{~W}$. (The QCM measurements starts $9 \mathrm{~s}$ after plasma ignition to allow for enough time to stabilize the deposition process and thereby ensure stable and repeatable data acquisition). 
To study the surface chemistry and to monitor the film deposition in our CVD method, a continuous time-dependent CVD process was employed. Here, the Fe precursor and the plasma discharge were individually pulsed into the system with a pulsing time of $5 \mathrm{~s} \mathrm{FeCp}_{2}$ followed by a 5 s plasma, Fig. 5.9. More details can be found in Paper IV of this thesis.

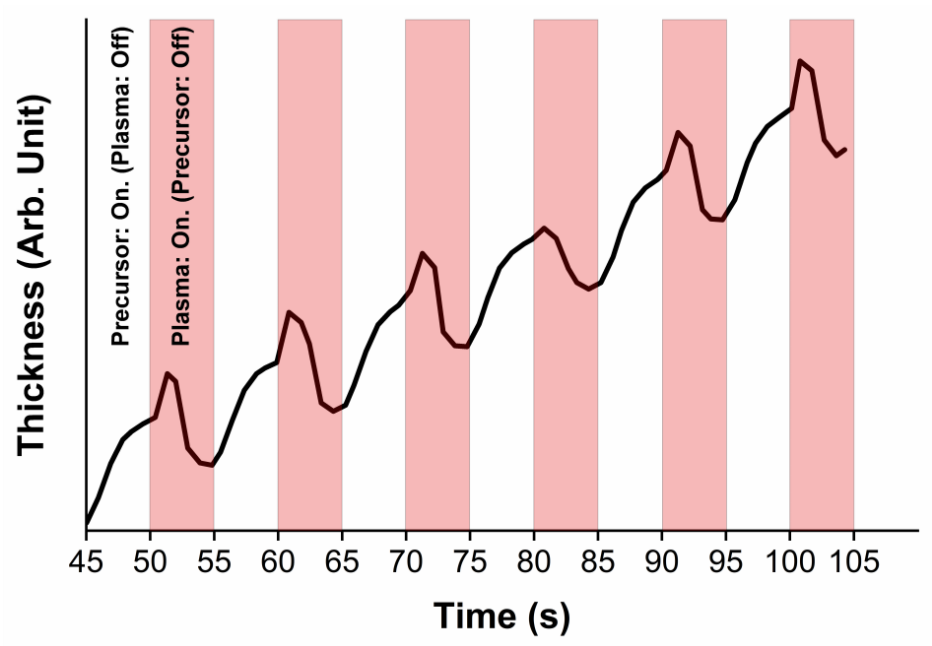

FIGURE 5.9. QCM measurements of Fe film growth during a time-dependent CVD process where the Fe precursor and the plasma discharge are individually pulsed with a pulsing time of $5 \mathrm{~s} \mathrm{FeCp}_{2}$ followed by a $5 \mathrm{~s}$ plasma $(10 \mathrm{~W})$. The QCM crystal is used as a substrate with a bias voltage of $+40 \mathrm{~V}(\mathrm{DC})$. The figure shows a snapshot of the deposition process.

The biased QCM system presented here is a new approach of using QCM and have not reported before for such applications. Also, the use of biased QCM together with a time-dependent CVD approach show the potential of this QCM system to unveil details of the surface chemistry of the newly developed CVD method where plasma electrons are used as reducing agents for metal deposition. 


\section{Outlook}

The continuous advancing in technologies, including the miniaturization of electronics, require continuous advances of material science. Over the last decades, CVD has shown an exceptional development to meet the requirements set in various fields and applications, especially in electronics where thin films have prerequisite functions. There is no doubt that CVD is a state-of-art technique for thin film deposition for a broad variety of applications. The constant advancement in CVD opens not only new opportunities, but also challenges that need to be processed, understood, and addressed. For instance, film processing for electronic applications restricts the usage of high temperatures in CVD. Introducing plasma as a source of energy (PECVD), allow film processing at lower temperatures that can be applied for such applications. Nevertheless, using plasma usually leads to increase the process complexity and may cause substrate/surface damage.

Therefore, in Paper I, I introduce a new CVD method where I use one component of the plasma, i.e., only the free plasma electrons as reducing agents to deposit metal films. Since our new CVD method relies only on the electrons-precursors surface chemical reactions and the plasma volume reactions do not ideally occur, the new method differs from conventional CVD and PECVD. It is worth mentioning, that our CVD method, where plasma electrons are used as reducing agents, with positively biased substrate, has not been reported before, which is confirmed by a granted patent application [Nadhom, H. Pedersen, H. A method and apparatus for chemical vapour deposition and a Fin field-effect transistor. 1950124-6. Granted 2021] (can also be found as Appendix I in this thesis).

I have this far showed that the newly developed CVD method can be used to deposit metallic films of iron, cobalt, and nickel as a prove of concept. I have also showed that pure metals (without oxides) are achievable by this method (where XPS shows metallic peaks in the as-received sample, Fig. 5.6 and 6.1). Thence, we believe our method opens up for many new exciting opportunities and possibilities that can revolutionize metal thin films deposition in many important areas. For instance, the work in Paper I and II can be exploited for less complicated bottom-up manufacturing of semiconducting nanostructures of elemental semiconductors, such as $\mathrm{Si}$ and $\mathrm{Ge}$, for fin field-effect transistors (FinFET), where the processing steps could be reduced significantly. In addition, the ability of using temperature sensitive materials in the new CVD method (Paper III) can be further exploited for micro/nano 
pattering, and advanced to other conventional ASD materials, such as photoresists and SAMs, which offers additional approach for ASD in electronic fabrications.

To achieve such ambitions, further research and modifications of the new method are essential. For research, we need to understand the surface chemistry mechanism, to understand what control the deposition processes, by: additional analysis methods such as optical emission spectroscopy (OES); quantum chemical modeling; plasma studies using, e.g., Langmuir probe; and applying low frequency pulsed plasma, instead of continuous plasma, to decouple the plasma and surface chemistry (i.e., reduction when the plasma is on and chemisorption when the plasma is off) for additional understanding of the deposition processes. Modifications of the new method can be done by: reducing the deposition pressure, which reduces the oxygen and nitrogen levels, hence less film impurities; exploring other metal precursors (e.g., metal amidinates) to reduce the amount of carbon and oxygen in the film; exploring the deposition of other transition metals; using other hollow cathode insert materials (e.g., graphite) to minimize the physical sputtering effect, hence reducing the film impurities; exploring the heating of the substrate effect on the film growth and structure; and investigating other plasma gas source (e.g., Xe gas) to alter the electron temperatures.

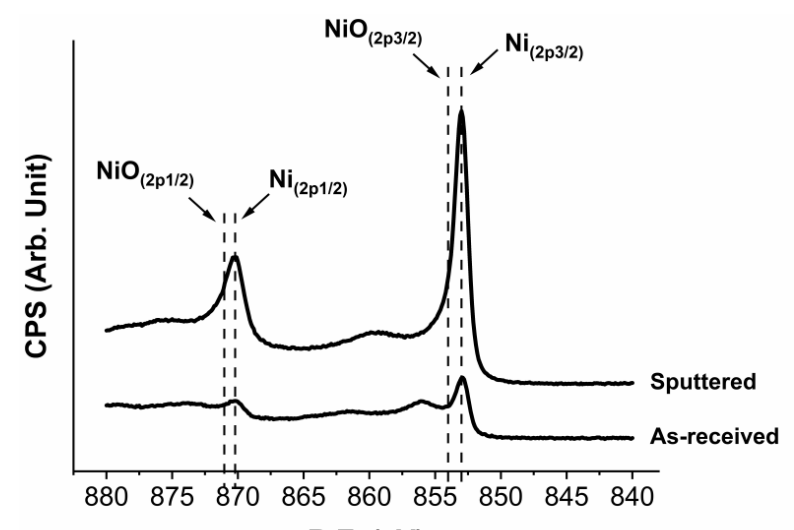

B.E. (eV)

FIGURE 6.1. High resolution XPS of nickel film deposited on $40 \mathrm{~nm} \mathrm{Ag/Si} \mathrm{before} \mathrm{and} \mathrm{after}$ sputter cleaning the surface. The as-received plot in the graph shows metallic Ni peak at the surface of the sample before being sputter cleaned. 


\section{References}

[1] J. E. Greene. Tracing the 5000-Year Recorded History of Inorganic Thin Films from 3000 BC to the Early 1900s AD. Appl. Phys. Rev. 1 (2014) 041302.

[2] E. D. Nicholson. The Ancient Craft of Gold Beating. Gold Bull. 12 (1979) 161.

[3] H. Frey and H. R. Khan, Eds. Handbook of Thin-Film Technology. Berlin, Heidelberg, Germany: Springer-Verlag Berlin Heidelberg, 2015.

[4] D. M. Mattox. Handbook of Physical Vapor Deposition (PVD) Processing, 2nd ed. Kidlington, Oxford, UK: William Andrew, 2010.

[5] K. S. Sree Harsha. Principles of Physical Vapor Deposition of Thin Films. Oxford, UK: Elsevier Science, 2006.

[6] A. C. Jones and M. L. Hitchman, Eds. Chemical vapour Deposition: Precursors, Processes and Applications. Cambrige, UK: RSC, 2009.

[7] M. Ohring. Materials Science of Thin Films, 2nd ed. San Diego, CA, USA: Academic Press, 2002.

[8] A. C. Jones and P. O'Brien. CVD of Compound Semiconductors: Precursor Synthesis, Development and Applications. Weinheim, Germany: VCH, 1997.

[9] M. L. Hitchman and K. F. Jensen, Eds. Chemical Vapor Deposition: Principles and Applications. London, UK: Academic Press, 1993.

[10] Y. Xu and X.-T. Yan. Chemical Vapour Deposition: An Integrated Engineering Design for Advanced Materials. London, UK: Springer-Verlag London Limited, 2010.

[11] D. M. Dobkin and M. K. Zuraw, Eds. Principles of Chemical Vapor Deposition. Dordrecht, Netherland: Kluwer Academic, 2003.

[12] P. O. Oviroh, R. Akbarzadeh, D. Pan, R. A. M. Coetzee, and T.-C. Jen. New Development of Atomic Layer Deposition: Processes, Methods and Applications. Sci. Technol. Adv. Mater. 20 (2019) 465.

[13] R. L. Puurunen. Surface Chemistry of Atomic Layer Deposition: A Case Study for the Trimethylaluminum/Water Process. J. Appl. Phys. 97 (2005) 121301.

[14] M. Mäkelä. Studies on Atomic Layer Deposition of Gold and Silver Thin Films., University of Helsinki, 2018.

[15] M. A. Lieberman and A. J. Lichtenberg. PRINCIPLES OF PLASMA DISCHARGES AND MATERIALS PROCESSING, 2nd ed. Hoboken, New Jersey, USA: Wiley, 2005.

[16] R. J. Goldenston and P. H. Rutherford. Introduction to Plasma Physics. Bristol, UK: IOP, 1995.

[17] F. F. Chen. Introduction to Plasma Physics and Controlled Fusion, 3rd ed. Cham Heidelberg New York Dordrecht London: Springer, 2016. 
[18] I. Safi. Recent Aspects Concerning DC Reactive Magnetron Sputtering of Thin Films: A Review. Surf. Coatings Technol. 127 (2000) 203.

[19] H. B. Profijt, M. C. M. van de Sanden, and W. M. M. Kessels. Substrate-Biasing during Plasma-Assisted Atomic Layer Deposition to Tailor Metal-Oxide Thin Film Growth. J. Vac. Sci. Technol. A 31 (2013) 01A106.

[20] N. Samal et al. Low-Temperature $\left(\leq 200^{\circ} \mathrm{C}\right)$ Plasma Enhanced Atomic Layer Deposition of Dense Titanium Nitride Thin Films. J. Vac. Sci. Technol. A 31 (2013) 01 A137.

[21] S. Ratzsch, E. B. Kley, A. Tünnermann, and A. Szeghalmi. Influence of the Oxygen Plasma Parameters on the Atomic Layer Deposition of Titanium Dioxide. Nanotechnology 26 (2015) 024003.

[22] H. Pedersen. Time as the Fourth Dimension: Opening up New Possibilities in Chemical Vapor Deposition. Chem. Mater. 28 (2016) 691.

[23] H. B. Profijt, S. E. Potts, M. C. M. van de Sanden, and W. M. M. Kessels. PlasmaAssisted Atomic Layer Deposition: Basics, Opportunities, and Challenges. J. Vac. Sci. Technol. A 29 (2011) 050801.

[24] S. B. S. Heil et al. Deposition of TiN and $\mathrm{HfO}_{2}$ in a Commercial $200 \mathrm{Mm}$ Remote Plasma Atomic Layer Deposition Reactor. J. Vac. Sci. Technol. A 25 (2007) 1357.

[25] S. Muhl and A. Pérez. The Use of Hollow Cathodes in Deposition Processes: A Critical Review. Thin Solid Films 579 (2015) 174.

[26] M. I. Hasan, I. Pilch, D. Söderström, D. Lundin, U. Helmersson, and N. Brenning. Modeling the Extraction of Sputtered Metal from High Power Impulse Hollow Cathode Discharges. Plasma Sources Sci. Technol. 22 (2013) 035006.

[27] L. Bárdoš. Radio Frequency Hollow Cathodes for the Plasma Processing Technology. Surf. Coatings Technol. 86-87 (1996) 648.

[28] Y. Yamamura and H. Tawara. Energy Dependence of Ion-Induced Sputtering Yields from Monatomic Solids at Normal Incidence. At. Data Nucl. Data Tables 62 (1996) 149.

[29] S. E. Koponen, P. G. Gordon, and S. T. Barry. Principles of Precursor Design for Vapour Deposition Methods. Polyhedron 108 (2016) 59.

[30] K. Väyrynen. Atomic Layer Deposition of Late First-Row Transition Metals: Precursors and Processes., University of Helsinki, 2019.

[31] A. Gasparotto, G. Carraro, C. Maccato, and D. Barreca. On the Use of Fe(dpm) 3 as Precursor for the Thermal-CVD Growth of Hematite Nanostructures. Phys. Status Solidi A 214 (2017) 1.

[32] T. J. Knisley, L. C. Kalutarage, and C. H. Winter. Precursors and Chemistry for the Atomic Layer Deposition of Metallic First Row Transition Metal Films. Coord. Chem. Rev. 257 (2013) 3222.

[33] A. Devi. "Old Chemistries" for New Applications: Perspectives for Development of Precursors for MOCVD and ALD Applications. Coord. Chem. Rev. 257 (2013) 3332.

[34] B. S. Lim, A. Rahtu, J. S. Park, and R. G. Gordon. Synthesis and Characterization of Volatile, Thermally Stable, Reactive Transition Metal Amidinates. Inorg. Chem. 42 (2003) 7951. 
[35] S. T. Barry. Amidinates, Guanidinates and Iminopyrrolidinates: Understanding Precursor Thermolysis to Design a Better Ligand. Coord. Chem. Rev. 257 (2013) 3192.

[36] X. Li, N. C. Fan, and H. J. Fan. A Micro-Pulse Process of Atomic Layer Deposition of Iron Oxide Using Ferrocene and Ozone Precursors and Ti-Doping. Chem. Vap. Depos. 19 (2013) 104.

[37] A. B. F. Martinson et al. Atomic Layer Deposition of $\mathrm{Fe}_{2} \mathrm{O}_{3}$ Using Ferrocene and Ozone. J. Phys. Chem. C 115 (2011) 4333.

[38] M. Rooth, A. Johansson, K. Kukli, J. Aarik, M. Boman, and A. Hårsta. Atomic Layer Deposition of Iron Oxide Thin Films and Nanotubes Using Ferrocene and Oxygen as Precursors. Chem. Vap. Depos. 14 (2008) 67.

[39] I.-K. Oh, H. Kim, and H.-B.-R. Lee. Growth Mechanism of Co Thin Films Formed by Plasma-Enhanced Atomic Layer Deposition Using $\mathrm{NH}_{3}$ as Plasma Reactant. Curr. Appl. Phys. 17 (2017) 333.

[40] D. J. Hagen, M. E. Pemble, and M. Karppinen. Atomic Layer Deposition of Metals: Precursors and Film Growth. Appl. Phys. Rev. (2019) 041309.

[41] J. Chae, H. S. Park, and S. W. Kang. Atomic Layer Deposition of Nickel by the Reduction of Preformed Nickel Oxide. Electrochem. Solid-State Lett. 5 (2002) C64.

[42] L. Brissonneau and C. Vahlas. MOCVD-Processed Ni Films from Nickelocene. Part I: Growth Rate and Morphology. Chem. Vap. Depos. 5 (1999) 135.

[43] M. K. Singh, Y. Yang, and C. G. Takoudis. Low-Pressure Metallorganic Chemical Vapor Deposition of $\mathrm{Fe}_{2} \mathrm{O}_{3}$ Thin Films on $\mathrm{Si}(100)$ Using n-Butylferrocene and Oxygen. $J$. Electrochem. Soc. 155 (2008) D618.

[44] W. M. Haynes, Ed. CRC Handbook of Chemistry and Physics, 97th ed. Boca Raton, FL, USA: CRC Press, 2017.

[45] A. A. Vasiliev and M. A. Polykarpov. Change of Ferric Oxide $\left(\mathrm{Fe}_{2} \mathrm{O}_{3}\right)$ Semiconductor Conductivity Type in the Interaction with Reducing Gases. Sensors Actuators B 7 (1992) 626.

[46] W. Kudernatsch et al. Direct Visualization of Catalytically Active Sites at the FeO$\operatorname{Pt}(111)$ Interface. ACS Nano 9 (2015) 7804.

[47] Y.-N. Sun et al. Monolayer Iron Oxide Film on Platinum Promotes Low Temperature CO Oxidation. J. Catal. 266 (2009) 359.

[48] Y. Luo, S. K. Kang, O. Jinka, M. Mason, S. A. Cordes, and L. T. Romankiw. Development of Electroless Nickel-Iron Plating Process for Microelectronic Applications., in IEEE 64th Electronic Components and Technology Conference (ECTC), 2014, 1782.

[49] P. Kumar. Magnetic Behavior of Surface Nanostructured 50-nm Nickel Thin Films. Nanoscale Res. Lett. 5 (2010) 1596.

[50] Y. Shiratsuchi, T. Nakatani, S. I. Kawahara, and R. Nakatani. Magnetic Coupling at Interface of Ultrathin Co Film and Antiferromagnetic $\mathrm{Cr}_{2} \mathrm{O}_{3}(0001)$ Film. J. Appl. Phys. 106 (2009) 033903. 
[51] D. V Dimitrov, G. C. Hadjipanayis, V. Papaefthymiou, and A. Simopoulos. Magnetic Properties and Microstructure of Fe-O and CO-O Thin Films. IEEE Trans. Magn. 33 (1999) 4363.

[52] C. A. F. Vaz, J. A. C. Bland, and G. Lauhoff. Magnetism in Ultrathin Film Structures. Reports Prog. Phys. 71 (2008) 056501.

[53] S. H. Kang. Recent Advances in Spintronics for Emerging Memory Devices. MagnetoElectric Nanostructures 60 (2008) 28.

[54] R. S. Sundar and S. C. Deevi. Soft magnetic FeCo alloys: alloy development, processing, and properties, 50.2005.

[55] D. Chiba, S. Fukami, K. Shimamura, N. Ishiwata, K. Kobayashi, and T. Ono. Electrical Control of the Ferromagnetic Phase Transition in Cobalt at Room Temperature. Nat. Mater. 10 (2011) 853.

[56] S. Wolf. SILICON PROCESSING FOR THE VLSI ERA Vol.4 - Deep-Submicron Process Technology. Sunset Beach, CA, USA: Lattice Press, 2002.

[57] D. C. Harris. Quantitative Chemical Analysis, 5th ed. New York. USA: W. H. Freeman and Company, 1999.

[58] S. Park, S. Lim, and H. Choi. Chemical Vapor Deposition of Iron and Iron Oxide Thin Films from Fe(II) Dihydride Complexes. Chem. Mater. 18 (2006) 5150.

[59] E. Pousaneh et al. Iron(III) $\beta$-Diketonates: CVD Precursors for Iron Oxide Film Formation. Inorganica Chim. Acta 487 (2019) 1.

[60] D. Peeters et al. Nanostructured $\mathrm{Fe}_{2} \mathrm{O}_{3}$ Processing via Water-Assisted ALD and LowTemperature CVD from a Versatile Iron Ketoiminate Precursor. Adv. Mater. Interfaces (2017) 1700155.

[61] A. Martinez, J. Pena, M. Labeau, J. M. González-Calbet, and M. Vallet-Reg. The Deposition of $\alpha-\mathrm{Fe}_{2} \mathrm{O}_{3}$ by Aerosol Chemical Vapor Deposition. J. Mater. Res. 10 (1995) 1307.

[62] H. Choi, S. Park, and H. G. Jang. Chemical Vapor Deposition of Cobalt Using Novel Cobalt(I) Precursors. J. Mater. Res. 17 (2002) 267.

[63] T. Maruyama. Cobalt Thin Films Prepared by Chemical Vapor Deposition from Cobaltous Acetate. Appl. Phys. Lett. 59 (1991) 1433.

[64] J. Lee et al. Highly Conformal Deposition of Pure Co Films by MOCVD Using $\mathrm{Co}_{2}(\mathrm{CO})_{8}$ as a Precursor. J. Electrochem. Soc. 153 (2006) G539.

[65] D.-X. Ye et al. Low Temperature Chemical Vapor Deposition of Co Thin Films from $\mathrm{Co}_{2}(\mathrm{CO})_{8}$. Thin Solid Films 485 (2005) 95.

[66] N. Samal, K. B. Chetry, K. Rook, A. Hayes, and A. Devasahayam. Low-Temperature ( $\leq$ $\left.150{ }^{\circ} \mathrm{C}\right)$ Chemical Vapor Deposition of Pure Cobalt Thin Films. J. Vac. Sci. Technol. B 32 (2014) 011206.

[67] T. Maruyama and T. Tago. Nickel Thin Films Prepared by Chemical Vapour Deposition from Nickel Acetylacetonate. J. Mater. Sci. 28 (1993) 5345. 
[68] G. Carraro et al. An Old Workhorse for New Applications: Fe(dpm) $)_{3}$ as a Precursor for Low-Temperature PECVD of Iron(III) Oxide. Phys. Chem. Chem. Phys. 17 (2015) 11174.

[69] C. Guyon, A. Barkallah, F. Rousseau, K. Giffard, D. Morvan, and M. Tatoulian. Deposition of Cobalt Oxide Thin Films by Plasma-Enhanced Chemical Vapour Deposition (PECVD) for Catalytic Applications. Surf. Coatings Technol. 206 (2011) 1673.

[70] J. R. Avila, D. W. Kim, M. Rimoldi, O. K. Farha, and J. T. Hupp. Fabrication of Thin Films of $\alpha-\mathrm{Fe}_{2} \mathrm{O}_{3}$ via Atomic Layer Deposition Using Iron Bisamidinate and Water under Mild Growth Conditions. ACS Appl. Mater. Interfaces 7 (2015) 16138.

[71] S. Selvaraj, H. Moon, J. Y. Yun, and D. H. Kim. Iron Oxide Grown by Low-Temperature Atomic Layer Deposition. Korean J. Chem. Eng. 33 (2016) 3516.

[72] Y. Zhang, M. Liu, Y. Zhang, X. Chen, W. Ren, and Z. G. Ye. Atomic Layer Deposition of Superparamagnetic and Ferrimagnetic Magnetite Thin Films. J. Appl. Phys. 117 (2015) 17 C743.

[73] R. K. Ramachandran, J. Dendooven, and C. Detavernier. Plasma Enhanced Atomic Layer Deposition of $\mathrm{Fe}_{2} \mathrm{O}_{3}$ Thin Films. J. Mater. Chem. A 2 (2014) 10662.

[74] D.-M. Tyler, Elko-Hansen, and J. G. Ekerdt. XPS Investigation of the Atomic Layer Deposition Half Reactions of Bis(n-tert-butyl-n'-ethylpropionamidinato) Cobalt(II). Chem. Mater. 26 (2014) 2642.

[75] T. D. M. Elko-Hansen, A. Dolocan, and J. G. Ekerdt. Atomic Interdiffusion and Diffusive Stabilization of Cobalt by Copper during Atomic Layer Deposition from Bis(ntert-butyl-n'-ethylpropionamidinato) Cobalt(II). J. Phys. Chem. Lett. 5 (2014) 1091.

[76] K. Väyrynen et al. Diamine Adduct of Cobalt(II) Chloride as a Precursor for Atomic Layer Deposition of Stoichiometric Cobalt(II) Oxide and Reduction Thereof to Cobalt Metal Thin Films. Chem. Mater. 30 (2018) 3499.

[77] H. B. R. Lee, W. H. Kim, Y. Park, S. Baik, and H. Kim.Cobalt and Nickel Atomic Layer Depositions for Contact Applications., in IEEE International Interconnect Technology Conference, IITC, 2009, 157.

[78] K. W. Do et al. Formation of Low-Resistivity Nickel Silicide with High Temperature Stability from Atomic-Layer-Deposited Nickel Thin Film. Jpn. J. Appl. Phys. 45 (2006) 2975.

[79] B. Zhu, Z.-J. Ding, X. Wu, W.-J. Liu, D. W. Zhang, and S.-J. Ding. Plasma-Enhanced Atomic Layer Deposition of Cobalt Films Using $\mathrm{Co}(\mathrm{EtCp})_{2}$ as a Metal Precursor. Nanoscale Res. Lett. 14 (2019) 1.

[80] H.-B.-R. Lee and H. Kim. High-Quality Cobalt Thin Films by Plasma-Enhanced Atomic Layer Deposition. Electrochem. Solid-State Lett. 9 (2006) G323.

[81] M. C. Giordano et al. Plasma-Enhanced Atomic Layer Deposition of Nickel Nanotubes with Low Resistivity and Coherent Magnetization Dynamics for 3D Spintronics. ACS Appl. Mater. Interfaces 12 (2020) 40443.

[82] J. P. Klesko, M. M. Kerrigan, and C. H. Winter. Low Temperature Thermal Atomic Layer Deposition of Cobalt Metal Films. Chem. Mater. 28 (2016) 700. 
[83] K. Cao, J. Cai, X. Liu, and R. Chen. Review Article: Catalysts Design and Synthesis via Selective Atomic Layer Deposition. J. Vac. Sci. Technol. A 36 (2018) 010801.

[84] A. J. M. Mackus et al. Atomic Layer Deposition of Pd and Pt Nanoparticles for Catalysis: On the Mechanisms of Nanoparticle Formation. Nanotechnology 27 (2016) 034001.

[85] A. J. M. Mackus, M. J. M. Merkx, and W. M. M. Kessels. From the Bottom-Up: Toward Area-Selective Atomic Layer Deposition with High Selectivity. Chem. Mater. 31 (2019) 2.

[86] G. N. Parsons and R. D. Clark. Area-Selective Deposition: Fundamentals, Applications, and Future Outlook. Chem. Mater. 32 (2020) 4920.

[87] T. Ito and S. Okazaki. Pushing the Limits of Lithography. Nature 406 (2000) 1027.

[88] B. Gorzolnik, P. Mela, and M. Moeller. Nano-Structured Micropatterns by Combination of Block Copolymer Self-Assembly and UV Photolithography. Nanotechnology 17 (2006) 5027.

[89] J. A. Singh et al. Area-Selective Atomic Layer Deposition of Metal Oxides on Noble Metals through Catalytic Oxygen Activation. Chem. Mater. 30 (2018) 663.

[90] E. Färm, S. Lindroos, M. Ritala, and M. Leskelä. Microcontact Printed $\mathrm{RuO}_{\mathrm{x}}$ Film as an Activation Layer for Selective-Area Atomic Layer Deposition of Ruthenium. Chem. Mater. 24 (2012) 275.

[91] A. J. M. MacKus, J. J. L. Mulders, M. C. M. Van De Sanden, and W. M. M. Kessels. Local Deposition of High-Purity Pt Nanostructures by Combining Electron Beam Induced Deposition and Atomic Layer Deposition. J. Appl. Phys. 107 (2010) 116102.

[92] F. S. M. Hashemi, B. R. Birchansky, and S. F. Bent. Selective Deposition of Dielectrics: Limits and Advantages of Alkanethiol Blocking Agents on Metal-Dielectric Patterns. ACS Appl. Mater. Interfaces 8 (2016) 33264.

[93] R. Chen, H. Kim, P. C. McIntyre, and S. F. Bent. Investigation of Self-Assembled Monolayer Resists for Hafnium Dioxide Atomic Layer Deposition. Chem. Mater. 17 (2005) 536.

[94] D. Bobb-Semple, K. L. Nardi, N. Draeger, D. M. Hausmann, and S. F. Bent. AreaSelective Atomic Layer Deposition Assisted by Self-Assembled Monolayers: A Comparison of $\mathrm{Cu}, \mathrm{Co}, \mathrm{W}$, and Ru. Chem. Mater. 31 (2019) 1635.

[95] W.-H. Kim et al. A Process for Topographically Selective Deposition on 3D Nanostructures by Ion Implantation. ACS Nano 10 (2016) 4451.

[96] M. J. M. Merkx, S. Vlaanderen, T. Faraz, M. A. Verheijen, W. M. M. Kessels, and A. J. M. Mackus. Area-Selective Atomic Layer Deposition of TiN Using Aromatic Inhibitor Molecules for Metal/Dielectric Selectivity. Chem. Mater. 32 (2020) 7788.

[97] B. Kalanyan, P. C. Lemaire, S. E. Atanasov, M. J. Ritz, and G. N. Parsons. Using Hydrogen To Expand the Inherent Substrate Selectivity Window During Tungsten Atomic Layer Deposition. Chem. Mater. 28 (2016) 117.

[98] E. Mohimi, Z. V Zhang, S. Liu, J. L. Mallek, G. S. Girolami, and J. R. Abelson. Area Selective CVD of Metallic Films from Molybdenum, Iron, and Ruthenium Carbonyl Precursors: Use of Ammonia to Inhibit Nucleation on Oxide Surfaces. J. Vac. Sci. Technol. A 36 (2018) 041507. 
[99] M. M. Kerrigan et al. Substrate Selectivity in the Low Temperature Atomic Layer Deposition of Cobalt Metal Films from Bis(1,4-di-tert-butyl-1,3-diazadienyl)Cobalt and Formic Acid. J. Chem. Phys. 146 (2017) 052813.

[100] M. F. J. Vos et al. Area-Selective Deposition of Ruthenium by Combining Atomic Layer Deposition and Selective Etching. Chem. Mater. 31 (2019) 3878.

[101] C. Zhang, J. Kalliomäki, M. Leskelä, and M. Ritala. Patterned Films by Atomic Layer Deposition Using Parafilm as a Mask. J. Vac. Sci. Technol. A 36 (2018) $01 \mathrm{~B} 102$.

[102] M. Forouzmehr et al. Selective Atomic Layer Deposition on Flexible Polymeric Substrates Employing a Polyimide Adhesive as a Physical Mask. J. Vac. Sci. Technol. A 39 (2021) 012405.

[103] M. J. Hampden-Smith and T. T. Kodas. Chemical Vapor Deposition of Metals: Part 2. Overview of Selective CVD of Metals. Chem. Vap. Depos. 1 (1995) 39.

[104] W. L. Gladfelter. Selective Metalization by Chemical Vapor Deposition. Chem. Mater. 5 (1993) 1372.

[105] G. N. Parsons, J. J. Boland, and J. C. Tsang. Selective Deposition and Bond Strain Relaxation in Silicon PECVD Using Time Modulated Silane Flow. Jpn. J. Appl. Phys. 31 (1992) 1943.

[106] G. Akiki, D. Suchet, D. Daineka, S. Filonovich, P. Bulkin, and E. V. Johnson. Area Selective Deposition of Silicon by Plasma Enhanced Chemical Vapor Deposition Using a Fluorinated Precursor. Appl. Surf. Sci. 531 (2020) 147305.

[107] C. Vallée et al. Plasma Deposition-Impact of Ions in Plasma Enhanced Chemical Vapor Deposition, Plasma Enhanced Atomic Layer Deposition, and Applications to Area Selective Deposition. J. Vac. Sci. Technol. A 38 (2020) 033007.

[108] Y. H. Low, M. F. Bain, D. C. S. Bien, J. H. Montgomery, B. M. Armstrong, and H. S. Gamble. Selective Deposition of CVD Iron on Silicon Dioxide and Tungsten. Microelectron. Eng. 83 (2006) 2229.

[109] Z. V. Zhang, S. Liu, G. S. Girolami, and J. R. Abelson. Area-Selective Chemical Vapor Deposition of Cobalt from Dicobalt Octacarbonyl: Enhancement of Dielectric-Dielectric Selectivity by Adding a Coflow of $\mathrm{NH}_{3}$. J. Vac. Sci. Technol. A 38 (2020) 033401.

[110] S. W. Ryu, S. Kim, J. Yoon, J. T. Tanskanen, H. Kim, and H.-B.-R. Lee. Area-Selective Chemical Vapor Deposition of Co for Cu Capping Layer. Curr. Appl. Phys. 16 (2016) 88 .

[111] H.-B.-R. Lee and H. Kim. Area Selective Atomic Layer Deposition of Cobalt Thin Films. ECS Trans. 16 (2008) 219.

[112] A. H. Simon et al. Electromigration Comparison of Selective CVD Cobalt Capping with PVD $\mathrm{Ta}(\mathrm{N})$ and CVD Cobalt Liners on 22nm-Groundrule Dual-Damascene $\mathrm{Cu}$ Interconnects., 2013.

[113] M. Kim et al. Atomic Layer Deposition of Nickel Using a Heteroleptic Ni Precursor with $\mathrm{NH}_{3}$ and Selective Deposition on Defects of Graphene. ACS Omega 4 (2019) 11126.

[114] M. M. Kerrigan, J. P. Klesko, K. J. Blakeney, and C. H. Winter. Low Temperature, Selective Atomic Layer Deposition of Nickel Metal Thin Films. ACS Appl. Mater. Interfaces 10 (2018) 14200. 
[115] M. M. Kerrigan, J. P. Klesko, and C. H. Winter. Low Temperature, Selective Atomic Layer Deposition of Cobalt Metal Films Using Bis(1,4-di-tert-butyl-1,3diazadienyl)Cobalt and Alkylamine Precursors. Chem. Mater. 29 (2017) 7458.

[116] J. I. Goldstein, D. E. Newbury, J. R. Michael, N. W. M. Ritchie, J. H. J. Scott, and D. C. Joy. Scanning Electron Microscopy and X-Ray Microanalysis, 4th ed. New York, NY, USA: Springer Science, 2018.

[117] R. Jenkins and J. L. De Vries. Practical X-Ray Spectrometry, 2nd ed. New York, NY, USA: Springer-Verlag New York, 1972.

[118] M. Khan, Ed. THE TRANSMISSION ELECTRON MICROSCOPY. Rijeka, Croatia: InTech, 2012.

[119] S. Hüfner. Photoelectron Spectroscopy: Principles and Applications, 3rd ed. New York, NY, USA: Springer-Verlag Berlin Heidelberg, 2003.

[120] J. M. Wagner, Ed. X-Ray Photoelectron Spectroscopy. New York, NY, USA: Nova Science, 2011.

[121] P. Van Der Heide. X-RAY PHOTOELECTRON SPECTROSCOPY: An Introduction to Principles and Practices. Hoboken, New Jersey, USA: John Wiley \& Sons, 2012.

[122] S. Hofmann. Auger- and X-Ray Photoelectron Spectroscopy in Materials Science: A User-Oriented Guide. Berlin, Heidelberg, Germany: Springer-Verlag Berlin Heidelberg, 2013

[123] A. G. Sault. Quantitative Analysis of Auger Lineshapes of Oxidized Iron. Appl. Surf. Sci. 74 (1994) 249.

[124] D. L. Peng, K. Sumiyama, M. Oku, T. J. Konno, K. Wagatsuma, and K. Suzuki. X-Ray Diffraction and X-Ray Photoelectron Spectra of Fe-Cr-N Films Deposited by DC Reactive Sputtering. J. Mater. Sci. 34 (1999) 4623.

[125] J. F. Moulder, W. F. Stickle, P. E. Sobol, and K. D. Bomben. Handbook of X-ray Photoelectron Spectroscopy, 2nd ed. Eden Prairie, Minnesota, USA: Perkin-Elmer Corporation, Physical Electronics Division, 1992.

[126] S. Sato, H. Honjo, S. Ikeda, H. Ohno, T. Endoh, and M. Niwa. Evidence of a Reduction Reaction of Oxidized Iron/Cobalt by Boron Atoms Diffused toward Naturally Oxidized Surface of CoFeB Layer during Annealing. Appl. Phys. Lett. 106 (2015) 142407.

[127] C. J. Powell. Recommended Auger Parameters for 42 Elemental Solids. J. Electron Spectros. Relat. Phenomena 185 (2012) 1.

[128] M. C. Biesinger et al. Applied Surface Science Resolving Surface Chemical States in XPS Analysis of First Row Transition Metals, Oxides and Hydroxides : Cr , Mn , Fe , Co and Ni. Appl. Surf. Sci. 257 (2011) 2717.

[129] A. N. Mansour. Nickel Monochromated Al Ka XPS Spectra from the Physical Electronics Model 5400 Spectrometer. Surf. Sci. Spectra 3 (1994) 221.

[130] A. N. Mansour. Characterization of NiO by XPS. Surf. Sci. Spectra 3 (1994) 231.

[131] A. N. Mansour. Characterization of $\beta \mathrm{Ni}(\mathrm{OH})_{2}$ by XPS. Surf. Sci. Spectra 3 (1994) 239. 
[132] A. Mondal, S. Maiti, S. Mahanty, and A. Baran Panda. Large-Scale Synthesis of Porous $\mathrm{NiCo}_{2} \mathrm{O}_{4}$ and $\mathrm{rGO}-\mathrm{NiCO}_{2} \mathrm{O}_{4}$ Hollow-Spheres with Superior Electrochemical Performance as a Faradaic Electrode. J. Mater. Chem. A 5 (2017) 1.

[133] M. Varga et al. Diamond/Carbon Nanotube Composites: Raman, FTIR and XPS Spectroscopic Studies. Carbon N. Y. 111 (2017) 54.

[134] N. Dwivedi, R. J. Yeo, N. Satyanarayana, S. Kundu, S. Tripathy, and C. S. Bhatia. Understanding the Role of Nitrogen in Plasma-Assisted Surface Modification of Magnetic Recording Media with and without Ultrathin Carbon Overcoats. Sci. Rep. 5 (2015) 7772.

[135] M. Birkholz. Thin Film Analysis by X-Ray Scattering. Weinheim, Germany: 2006 WILEY-VCH Verlag, 2006.

[136] J. Als-Nielsen and D. McMorrow. Elements of Moden X-ray Physics, 2nd ed. Chichester, West Sussex, UK: John Wiley \& Sons, 2011.

[137] D. Johannsmann. The Quartz Crystal Microbalance in Soft Matter Research: Fundamentals and Modeling. Heidelberg New York Dordrecht London: Springer, 2015.

[138] K. Cao, J. Cai, and R. Chen. Inherently Selective Atomic Layer Deposition and Applications. Chem. Mater. 32 (2020) 2195.

[139] J. Müller and L. D’or. Massenspektrometrische Untersuchungen an Dicyclopentadienylkomplexen Von Übergangsmetallen. J. Organomet. Chem. 10 (1967) 313.

[140] T. G. Rowland, B. Sztáray, and P. B. Armentrout. Metal-Cyclopentadienyl Bond Energies in Metallocene Cations Measured Using Threshold Collision-Induced Dissociation Mass Spectrometry. J. Phys. Chem. A 117 (2013) 1299.

[141] G. T. Stauf, D. C. Driscoll, P. A. Dowben, S. Barfuss, and M. Grade. Iron and Nickel Thin Film Deposition via Metallocene Decomposition. Thin Solid Films 153 (1987) 421.

[142] D. Welipitiya, P. A. Dowben, J. Zhang, W. W. Pai, and J. F. Wendelken. The Adsorption and Desorption of Ferrocene on Ag(100). Surf. Sci. 367 (1996) 20.

[143] C. M. Woodbridge, D. L. Pugmire, R. C. Johnson, N. M. Boag, and M. A. Langell. HREELS and XPS Studies of Ferrocene on Ag(100). J. Phys. Chem. B 104 (2000) 3085.

[144] D. L. Pugmire, C. M. Woodbridge, N. M. Boag, and M. A. Langell. Adsorption and Decomposition of Nickelocene on Ag(100): A High-Resolution Electron Energy Loss Spectroscopy and Temperature Programmed Desorption Study. Surf. Sci. 472 (2001) 155.

[145] Y. Wen et al. Edge-Selective Growth of $\mathrm{MCp}_{2}(\mathrm{M}=\mathrm{Fe}, \mathrm{Co}$, and Ni) Precursors on Pt Nanoparticles in Atomic Layer Deposition: A Combined Theoretical and Experimental Study. Chem. Mater. 31 (2019) A. 



\section{Papers}

The papers associated with this thesis have been removed for copyright reasons. For more details about these see:

http://urn.kb.se/resolve?urn=urn:nbn:se:liu:diva-175779 





\section{FACULTY OF SCIENCE AND ENGINEERING}

Linköping Studies in Science and Technology, Dissertation No. 2147, 2021

Department of Physics, Chemistry and Biology (IFM]

Linköping University

SE-581 83 Linköping, Sweden

www.liu.se 